PJOS 5(2), 2013

\title{
The conceptual metaphors of narrative structure: Gestural evidence for spatialized form in storytelling
}

\author{
Michael Kimmel $^{1}$ \\ University of Vienna
}

\begin{abstract}
This paper explores conceptual tools whereby narratively competent adults conceptualize the structure of literary events, as opposed to their scene content. My focus lies on how narrativity as a mode of thought is constituted through metanarrative discourse and what role embodied representations play in it. This global level of story cognition takes the form of conceptual metaphors such as TIME IS A PATH, CAUSALITY IS FORCE, or THEMATIC REALMS ARE SPACES/PLANES. Two kinds of evidence for this claim are combined: (a) linguistic metaphors for story gist, and, more extensively, (b) metaphorical gestures that accompany story summarization and commentary. Based on footage in which German literary critics discuss books, my specific task is to identify the various dimensions of story logic that gestures refer to. Overall, the data suggests that narrative form is systematically rooted in spatial logic and that dedicated structural devices dynamically co-evolve with the retelling of content. The study thus contributes a demonstration of Lakoff's (1987) "spatialization of form hypothesis", i.e. the wide ranging claim that structural cognition is rooted in image schemas.
\end{abstract}

\section{Introduction}

This article proposes to build a bridge between narratological and psychological research of story macro-structure. As matchmaker and third party I shall bring into play cognitive linguistic resources from conceptual metaphor theory, literary metaphor analysis, and gesture studies (cf. Herman, 2002; Brône and Vandaele, 2009). Harnessing these resources together can help us answer a crucial question about cognition: What conceptual devices do storytellers and recipients employ to structure their topic and bestow a narrative format on it? Formatting devices, in the way designated here, give rise to narrativity as such. They make stories different from other kinds of discourse and hand the speaker cognitive tools to create a specific perspective on a tale, "stage manage" it from a bird's-eye-view, and provide second-order reflections about its effects. When narrating, devices of this kind are an irreducible counterpart to scene content, because a story's meaning is also always structural meaning of the whole that emerges from temporal, causal and other relationships between individual aspects.

After briefly defining narrative form/format I relate this topic to image schemas. Then I move on to supporting data from two complementary angles. In Section 2 linguistic expressions referring to story gist provide an illustration of the many imageschematic conceptualizations of literary event structure. Evidence from cognitive linguistics and the psychology of events is additionally summoned. Section 3 turns to an extensive investigation of arguably the most persuasive source of data: metaphors expressed in co-speech gestures. It reports a pilot study of literary critics on TV and a web-channel whose gestures are indicative of flexibly deployed mappings from the spatial domain to story time, story themes, causality, and other aspects of narrative form. Although the corpus is too small to allow for generalizations it showcases a range of

\footnotetext{
${ }^{1}$ Email: michael.kimmel@univie.ac.at; michael.kimmel@gmx.at
} 
mappings used for construals of story logic, as well as typical laminations and worksharing patterns between gesture and speech. Section 4 then assumes a broader theoretical perspective, claiming that the data as a whole provides domain-specific proof for Lakoff's "spatialization of form hypothesis" and his notion of image-schematic ICM (Lakoff, 1987). My main wager is that spatial mappings help the literary critics structure the act of narration and organize their material. I take care to disentangle my principal functional claim about spatialized mappings from related, but non-identical claims about underlying conceptual metaphors and the dialectic between structure and content cues, respectively.

\subsection{Narrative structure}

When people understand an event - or narrative reflections thereof - they do not only process "what happens" at the level of content. What makes a story distinctly different from, say, mathematical problems, recipes, legal argumentation, or dada poetry is a particular causal-sequential format. A proper story is different from all these other kinds of discourse due, inter alia, to a specific format. For example, a certain narrative competence (cf. Fludernik, 1996) helps us to connect a visual scene from our favorite sitcom to that after the scene-break. We know by filmic genre convention, that of Hollywood's "continuity style", that any scene represents what happens after its precursor and is probably causally connected as its immediate outcome. This construction convention seems to go without saying because we perform it so frequently from early childhood onwards. Furthermore, narrative genres (mystery thrillers, romances, hero quests, etc.) are recognizable through certain structural signatures. E.g., Frederick Forsyth's thrillers all build tension by creating two or more parallel plots the reader switches between. Hence, many narrative operations arise from particular relationships between global form and meaning. However, unlike story content, people seldom become focally aware of the elementary structural dimensions of narrative. Readers, film and theater audiences simply apply them as background templates.

In addition, narrative structure defines what makes a "good story". This was first shown by Bartlett (1932) who exposed English readers to Native American stories that followed different cultural standards of storytelling. They found the stories lacking in the usual exposition-complication-resolution structure and distorted them to fit their cultural expectations when remembering them. Structuration thus defines narrative qua narrative. It is also relevant to esthetic effects, emotion, and attention. To provide a personal example, in watching Coppola's director's cut of Apocalypse Now it struck me that the two long scenes that had now been added, in which the protagonist stops his riverboat journey into Cambodia at a French plantation outpost and at a deluged military camp, are in themselves extremely well-acted, gripping, and interesting at the level of character development. Yet, I was left with a feeling that the original cut that had made it to the cinemas in 1979 had been more satisfying, because the story's main thrust, the riverboat journey itself was unbroken and could unfold its gradually intensifying effect without respite for the viewer. This feeling owed to narrative structure mainly, not content. The original cut avoids hierarchically embedded sub-plots and does not markedly shift the setting, the protagonists, or the temporal progression.

Psychological approaches to reading define narrative structure as compressed representations of story gist, key adages, morals, and main inferences (Graesser et al., 2002) or inferred story points like "one good turn deserves another". These may include inferences about the author's intention (Bortolussi and Dixon, 2003). As we shall see storytellers often take this unifying thematic perspective, as opposed to episode-based 
PJOS 5(2), 2013

summarizing (Zwaan et al., 2002: 41). Complementarily, many studies focus on how readers generate protagonist-related, causal, goal-related, temporal and spatial situation models and engage in event indexing (Zwaan, 1999; Zwaan et al., 2002). This means that the various story "tracks" are continuously monitored, updated, and integrated as time moves on, settings change, and new protagonists enter the scene. How readers integrate temporary and scene-bound situation models in longer-term memory is not quite the same thing as how high-level story points come about, which allow summary inferences about a narrative. While a sharply cut delineation between the two is hard to come by, they are not wholly discontinuous either (Zwaan et al., 2002). Therefore, structural knowledge can be said to include both story points and a more temporally extended image of the global plot progression across the chain of situation models. ${ }^{2}$

On a different note, story structure relates in various ways to the theoretical notion of metanarrative. Nünning (2001) couches the latter as reflexive commentary (as opposed, e.g., to metafictional disclosures of narrative artifactuality or paranarrative appellations to the audience). Examples for such commentary include stage directions like "we go back to the night before" and generalizing evaluative remarks. Of course, storytellers also comment on how an author presents the material (e.g. the rationale for including particular aspects or the chosen order), on the writing process or expected reader response (Fludernik, 2003).

Finally, I hold story structure and content to exhibit a mutually dynamizing, dialectical relationship. In part this reflects the fact that micro- and macro-structure mesh in reading, including text-driven and knowledge-driven aspects (cf. van Dijk and Kitsch, 1983). The present paper casts storytelling as a dynamic activity where form and content occupy mutually buttressing roles. I shall demonstrate that the relation between speech and co-speech gesture opens a window on how these two cognitive processes unfold in synchrony.

\subsection{The embodiment hypothesis}

Put in a nutshell my theoretical wager is that experiential gestalts, i.e. non-propositional representations of a topological or kinesthetic nature, structure the global textures of stories as if they were objects with extension, size, parts, content, motion, and offering the possibility to scan and manipulate them. This claim sits squarely with work on sensorimotor grounding of abstract concepts via image schemas (Gibbs, 2005, cf. Pecher and Zwaan, 2005). Concerning literature, specifically, image-schematic metaphors have been shown to inhere in event conceptualizations (Turner, 1996) and fulfill specific functional roles in theme-creation and symbolism (Danaher 2003; Kimmel 2005b, 2009), as well as protagonist characterization and plot generating interactions (Kimmel 2011a, $2011 \mathrm{~b}$ ). Yet other authors have highlighted gestalt processes in narrative foregrounding and focalization (Gavins and Steen, 2003; Tsur, 2009; Herman, 2009: 103ff).

From a psychological viewpoint, image schemas give rise to scaffolds enabling the reader to recognize a scene's generic logic. Whether or not details are imagined on top of this, minimal image-schematic ontologies are mandatory for representing intentionality and agency, as well as (inter-)action potentials of a setting and its participants. With

\footnotetext{
${ }^{2}$ For surveys of the psychological literature on narrative macro-structure and on thematics see Zacks and Tversky (2001), Bortolussi and Dixon (2003), and Louwerse and van Peer (2002). For surveys from traditional narratology see the entries on "events and event types", "narrative structure", "narrativity", "story grammars", "structuralist narratology", "time in narrative" in The Routledge Encyclopedia of Narrative Theory (Herman et al., 2005).
} 
respect to "who can do what" image schemas thus give rise to locomotion or object affordances and support quasi-perceptual inferences (Glenberg and Robertson, 2000). ${ }^{3}$ Summing this up, image schemas arise as a reflection of generic scene ontology, e.g. a protagonist (AGENT) being in a room (CONTAINER) and giving (PATH, FORCE) someone (FORCE RECIPIENT) an object (ENTITY) (see Gibbs, 2005).

Meanwhile, macro-aspects of narrative have either gone unnoticed or have not been made a focal topic under the embodied perspective. To remedy this, the present paper moves into the spotlight the act of conceptualizing narrative structure by studying mappings such as STORY SCENES ARE BOUNDED SPACES, STORY CAUSALITY IS FORCE, or PROTAGONIST GOALS ARE PATH-ENDPOINTS, wherein an embodied logic is metaphorically projected onto abstract narrative structure.

\section{Verbal metaphors of narrative structure}

What reason is there to believe that narrators and their audiences employ perceptually grounded sensorimotor knowledge to think about story structure? Everyday discourse about mundane events already holds important clues. Conventional metaphors indicate that event ontology is conceptualized in terms of image-schematic source domains. Thus, in English and many other languages we speak of PATHS for temporality ("as we go along", "further on in time"), of states as CONTAINERS ("she remained in that state", "what did you get me into?", "he jumped head-on into danger") and of causes as FORCES ("what drove you on?", "I was forced to do it") (cf. Lakoff and Johnson, 1999). Such phrase-level semantics is proto-narrative, but suggestive enough of narrative proper. After all, a long story can be compressed into a few phrases, with the summarized gist retaining the central inferences (Guindon and Kintsch, 1984). Conversely, many simple verbal phrases encapsulate events of some temporal extension and, not seldom, of internal phase structure, hereby constituting mini-narratives in nuce. It then stands to reason that relating an event's episodic detail involves similar image-schematic conceptualizations as summarizing it.

\subsection{Metanarrative metaphors}

The best method for tapping into genuinely structural representations is the study of discourse that summarizes and comments on stories. In metaphoric descriptions of a novel's or film's gist we talk about causality by referring to a story as "pushing ahead", being "dynamic" or "compelling", or having "thrust" (FORCE). We may also consider it as "lacking continuity" (BROKEN FORCE/LINK/PATH), as possessing a "main thread" (PATH, STRAIGHT), or as being "open-ended" (lack of CLOSURE). We talk about story partonomy as a drama having "four acts" (PART-WHOLE, INTERVAL), having "a central scene" (CENTER-PERIPHERY), and we might mention that a story appeared "neatly divided into self-contained sub-narratives" (BOUNDED OBJECT, APART) or that the narration seemed "repetitive" or "circular" (ITERATION). Aspects of temporality appear in speaking of "flashbacks", "flash-forwards", "temporal jumps" (PATHS, FORWARD, BACKWARD), a "straightforward" narration (STRAIGHT PATH), or a "constant shift between parallel

\footnotetext{
${ }^{3}$ Heider and Simmel (1944) demonstrate that we attribute agentive status to abstract shapes when these are moving in ways similar to human - and that is, intentional - motion. People asked to describe film-clips with abstract images say things like "the small triangle is chasing the large circle" or "the square is hiding from the circle". At some sort of image-schematic level the geometrical forms reproduced the dynamics of human behavioral patterns and thus allowed detecting affordances for "chasing" or "hiding".
} 
PJOS 5(2), 2013

temporalities" (two PATHS). Hierarchical structure is couched as "sub-plot", "insert", and "embedded tale" (NESTING). We talk about qualitative aspects of story content as "repetitive" (CYCLE), "kaleidoscopic" (MULTIPLEX), "diffuse" (UNBOUNDED) or "complex" (MULTIPLEX, NETWORK). Narratologists, in particular, also use concepts like "narrative disequilibrium" or "breaking stasis" (BALANCE) to speak about narration. Moreover, content related metaphors seem to carry over to descriptions of psychological or emotional impact on the reader, e.g. when a plot appears "forceful/compelling", "moving", "uplifting", "lame", (FORCE INTENSITY) or we talk of "tension" (FORCE ANTAGONISM) and "denouement" (FORCE RE-ENABLEMENT and possibly DECOMPLEXIFICATION OF STRUCTURE).

\subsection{Story wholes as contours and other holistic images}

Besides this focus on relations between parts (scenes, breakpoints, etc.) stories can also be globally perceived in their processual characteristics. One possibility is that contourlike qualities are ascribed, e.g. through cross-modal expressions like "ostinato", "crescendo", "smooth", "incisive", "abrupt", and so forth. Akin to a melody, contours grasp all the stages of the piece in continuity with one another. ${ }^{4}$ Most notably, we may speak of a story's diachronic flow (of interest, of affects, and so forth) as "rhapsodic" or saying it has a "peak". This holistically captures story evolution as a PATH with variations in INTENSITY, quite like how we perceive a melody or musical score (thus making INTENSITY a kind of super-schema that spans various modalities). An electromyography study by Robert Malmo (1975) on somatic correlates of reading strongly supports such holistic effects. He had subjects read detective stories while measuring their forehead tension and found that muscular activation rises "as the plot thickens", only to decline after its resolution. What is commonly called narrative tension or suspense thus reflects actual physical tension. We may interpret what Malmo's readers experienced as a global somatic arc of intensifying and then sharply dropping FORCE and perhaps the final denouement as reinstated BALANCE after disequilibrium (cf. Johnson, 1993: ch. 7).

Intensity over time, here realized as rising and falling tension, is by far not the only type of holistic gestalt. The author Milan Kundera (1988), himself from a musician's family, reports writing novels with an extended quasi-musical texture, beginning with an abstract idea of contrasts between adagio and prestissimo, etc. Other literary authors intuit images of "circles", "a zigzag" or a "sandwich" for story structure (Sadoski and Paivio, 2001:152-159). In all these cases, structural characteristics of scenes or whole stories are expressed as emergent gestalt properties (and, incidentally, suggest interesting parallels in how narratives and music are somatically perceived and enjoyed).

\subsection{The "stuff" of narrative: story tracks}

The literature on event conceptualization distinguishes causal, intentional, temporal, spatial, partonomy, and hierarchy aspects, as well as agent-related scene indexing (Zacks and Tversky, 2001; Zacks et al., 2001). The first three of these "tracks" are most crucial

\footnotetext{
${ }^{4}$ Beardsley (1958: 184, quoted after Grodal 1997: 164), says about this: “musical composition has [...] kinetic pattern: it is in the pattern of variation, in its propulsion, or intensity of movement [...] music, as a process in time, has varying regional qualities that can be described, metaphorically, by terms borrowed from physical motions: the music is rushing, hesitating, pausing, picking up speed, becoming calm, driving ahead, overcoming resistance, building up inertia." Brower's $(1997,2000)$ studies of musical melody, harmony, phrase structure, and form document the image schemas of ITERATION, CIRCULARITY, OVERLAP, and NESTING.
} 
for organizing a coherent macro-structural representation. In contrast, story entities such as people, objects, and ideas are monitored only when critical for understanding the structure of the situation (Zwaan et al., 2002: 38). Spatial details seem to be least important for a macro-structural model as long as readers read without special attention to these aspects (Zwaan, 1999). Precise layouts are primarily remembered when bearing on main story points, e.g. in Sherlock Holmes or Hercule Poirot whodunits, where the layout of a room is crucial to "solving the murder". After this brief overview, let us see how psychological research on story tracks can cross-fertilize with cognitive linguistic theory.

Causality. Story causality is essential to track (Zwaan, 1999) and a driving force for inferences (Trabasso and Suh, 1993). Readers are able to envisage a global causality from an opening to a closing event by connecting causal links between them. Being part of the main causal chain of a story (as well as being linked to many other sub-events) influences the recall, the likelihood of summarizing, and the judged importance of a sentence (Trabasso and Sperry, 1985; Trabasso and van den Broek, 1985). Yet, we have reason to think that complex chains are difficult to represent on the basis of propositional overlaps alone, thus making an imagistic aid valuable. The semantics of sentence level causation is known to involve metaphorical FORCES and PATHS (Turner, 1996: 29). Forces appear in, e.g., "The sight of blood forced him to run", paths in "Italian emerged from Latin", or combinations of the two in "Fear drove him to a situation he otherwise would have avoided." Notably the conceptual metaphor CAUSES ARE FORCES/MOVERS helps us reason. Applied to a story's scene-to-scene progression, an unbroken causal chain corresponds to multiple arcs in the "billiard ball model" (Langacker, 1987) with a FORCE-impetus being passed on from one event in a chain to the next. Continuity between episodes is thus conceptualized as an unbroken path. Alternatively, causal force disperses when a story line reaches a "dead end" or loose ends appear. Complex forms of causal hierarchy (Trabasso and van den Broek, 1985: 624) shall be discussed below.

Intentionality and goals comprise the agent-based aspect of causality. Although physical events or external circumstances may drive the plot, it frequently thrives on the protagonist's motivation, psychological causation, and enablement (i.e. necessary, but not sufficient precursor states) (Warren et al., 1979). When goal-directed actions move the plot forward this needs to be expressly represented. Basically, physical causation maps onto abstract psychological causation, as Lakoff and Johnson (1999) argue. Abstract goals inherit the logic of FORCE and SOURCE-PATH-GOAL schemas, for instance in a protagonist who wants to "pass an exam", "get somewhere with a new idea", or "make it up the social ladder". The agent is understood as exerting force and being in motion. The difference to mere physical causation lies in the AGENCY image schema, which we situate within the protagonist. Full agency thus requires active exertion of force and, especially, self-propelled motion. In line with this, Mandler (1992) proposes that infants acquire the image-schematic primitives ANIMACY, AGENCY, and GOAL, while Turner suggests the linguistic mappings ACTORS ARE MOVERS and ACTORS ARE MANIPULATORS (1996: 43).

Interestingly, prima facie non-agentive occurrences - i.e. they "simply happen" are commonly attributed to agents, from mundane expressions like "the stupid stone hit me" to literary personifications such as "The Grim Reaper". Specifically, we think of story events as being precipitated by external forces and protagonists as being moved by human antagonists such as a dominant parent or a foe, or by metaphysical forces such as faith, fate, or providence. We use the mappings EVENTS ARE ACTIONS as well as EVENTS ARE MOVERS ("Time marches on") and EVENTS ARE MANIPULATORS ("The drought is strangling us") (Turner, 1996: ch. 4). The same applies to the inner realm of people. An 
PJOS 5(2), 2013

emotional force like "courage" or "fear", as well as "the soul" or "inner drives" are forcedynamic antagonists that make a protagonist act, be it via FORCE ATTRACTION, STALEMATE/DEADLOCK, REPULSION, or DRIVING FORCE (Turner, 1996: 21; Talmy, 2000).

Kimmel (2011b) investigates literary force-dynamic conceptualizations which encapsulate the main conflict lines that give rise to plot dynamics and actancy (Greimas, 1966). This notably includes the relation between the focal protagonist and an opponent who thwarts her, but also helpers and beneficiaries. Couched in the force-dynamic schema, each specific kind of literary role distribution manifests a dynamic pattern, depending on whether the agonist and antagonist are thought of being in motion or static and depending on whether they are strong or weak. With respect to specific types of causation, Sweetser's (1990) research on modal verbs is also pertinent here. It reflects different realizations of causal force that are deeply embedded in our thought. Obligation is FORCE COMPULSION, permission is RESTRAINT REMOVAL, and ability is FORCE ENABLEMENT (cf. Johnson, 1987: 48ff), the latter being rooted in the experience of muscular pre-activation.

Temporality is tracked in some detail, facilitated by the obligatory marking of verb tense and aspect in many languages. First, as regards the reader's macroscopic overview, getting the order of episodes right is so crucial to comprehension that the conceptual story model is far better retained in memory than the - potentially jumbled text wording or propositional structure (Mandler, 1984). Creating a well-ordered mental story from discourse is often a non-trivial task, notably when the presentation order is non-linear or has gaps. With elisions, flash-forwards, flashbacks, or story threads being switched between conceptualizing the episodic order may become like assembling the pieces of a puzzle in a de- and re-composition process (PART-WHOLE). As I shall show, the generic mapping TIME IS SPACE (cf. Lakoff \& Johnson, 1999) can be put to various dynamic uses, notably using paths, path segments, and points on paths.

What is more, a storyteller may construe temporality with coarser or finer grain, with temporal extension or summarily, and with various process-related emphases. For instance, Herman (2002: 46f) observes that particular narrative genres have a preference for bounded sub-events, while others do not. Information about "event shape" is encoded in grammatical aspect and the aktionsart of a verb, be it perfective, imperfective, habitual, continuous, progressive and stative (Parrill, 2000). A gesture's manner of motion, to anticipate my later topic, is a good source for learning about the associated imagery. For instance, it can be smooth, gradual, repeated, or abrupt. It can reflect perfective or imperfective conceptualizations (i.e. construe the event as a homogenous unit vs. as a unit with internal structure). ${ }^{5}$ How event shape is construed has profound cognitive implications. Event constituents are more readily recalled with an imperfective aspect than with a perfective one (Ferretti et al., 2007). Similarly, telicity and decomposability influence how and if we simulate the event (Zwaan, 2008: 19ff.)

\footnotetext{
${ }^{5}$ Perfectives describe completed actions and are construed as units, not as internally complex. Imperfectives are temporally unbounded and internally complex, i.e. they profile component parts. Habituals are either states or activities and can involve multiple instances construed as units. Iterativity goes with oscillatory movements, while durativity entails continuous circular ones. Continuous aspect requires events to be construed as homogeneous, but dynamic, so that the phases are uniform but internally structured (and, usually, as involving energy consumption). Progressive aspect points to an ongoing process in which the internal components are different from each other and which involves change over time towards some goal. Stative aspect lacks energy input, and usually an agent. Reflecting these various characteristics of aspect, Narayanan's (1999) computational approach models a set of motor primitives (effort, boundedness, iteration, final state, duration).
} 
Story partonomy, i.e. a PART-WHOLE conceptualization, refers to scene and subscene structure (Zacks and Tversky, 2001) and derives from both causal and temporal aspects. As a story takes on shape a global partonomy emerges in the recipient's mind. Narratology offers its clientele of "academic storytellers" models in which partonomy is predicated on, e.g., Aristotle's exposition-development-complication-resolution schema or Labov's phase model of conversational storytelling. Those who retell stories may find partonomy-related memory particularly relevant to mentally navigate the episodic material. Unsurprisingly, breakpoints between episodes have a special status in memory (Boltz, 1992) and occur when protagonists, settings, and other items all change at the same time such that a new situation model must replace the old one. The breakpoints also typically align with goal structures (Zacks and Tversky, 2001: 16).

An element of hierarchy may add to partonomy proper, i.e. nested sub-goals within main goals (Mandler, 1984). Goals high up in the hierarchy are more quickly memorized (Foss and Bower, 1986) and lower levels may end up being collapsed in memory (Rumelhart, 1977; cf. Zacks et al., 2001: 13). Since a sub-goal needs to be satisfied for the superordinate goal to be resumed, the former can be though of as a kind of embedded segment. Especially in cases such as the Arabian Nights, where stories are mutually embedded or in framing tales like Heart of Darkness a NESTING schema is likely, i.e. a small PART contained in a larger WHOLE.

States and situations. Conceptualizing events as items with certain properties or contents is helpful for summarizing purposes. This includes metaphors based on containers, as in "in the situation" (Lakoff and Johnson, 1980), and on bounded objects, as in "handle a situation". As to the embodied basis of these scene containers, it is likely that story events, akin to perceptual events, are parsed by discontinuities and hereby create a kind of bounding in time and space (Zacks and Tversky, 2001). Imagined episodic breakpoints in stories have phenomenological characteristics in common with real perceptual boundaries: when one scene-bound situation model morphs into the next most properties in the flow of mental images change maximally (Zwaan et al., 2002). Second, key experiences of a protagonist may be conceptualized as bounded. This reflects the mapping EXPERIENTIAL STATES ARE CONTAINERS, which is well attested to linguistically ("I'm in shock"). Third and finally, some containers can come to stand for whole stories, as Buckland (2000: 54) stresses:

The narrative film in itself is understood as a container, as is evident in everyday comments people make after seeing a film - "There was not much in the film" (the evaluation of a film employs terms of quantity, or the more that happens, the better); 'I became immersed in (or absorbed into) the film' (here the spectator metaphorically views herself as an object drawn into the film as a container), and so on.

\subsection{Interim summary}

To recap, the prevalence of metaphoric expressions targeting an event's skeletal, yet basic ontology suggests that narratively competent speakers are, for certain purposes, able to think of stories as "events in time, which have no spatial shape, as having features of spatial shapes - continuity, extension, discreteness, completion, open-endedness, circularity, part-whole relations, and so on" (Turner, 1996: 18). 
PJOS 5(2), 2013

\section{Gestural metaphors of narrative structure}

For understanding how narrative structure unfolds the study of co-speech gestures that speakers use when telling, recounting, summarizing, or commenting on novels offers enormous leverage. When you, as a narratively competent adult, see a storyteller gesture you will inadvertently pick out topological and kinetic aspects from the gestural flow as meaningful. The storyteller on her part will inadvertently generate these patterns. Narrators create visible image-schematic structure all the time - this spans 3-D shaping or sculpting, 2-D drawing, pointing, embodying entities through a hand, tracing paths and organizing spaces, as well as through the kinetics of their gestures.

Gesture provides hands-on evidence about underlying representational formats. Because it is iconically displayed in the visual field gesture leaves little doubt that an iconic format is being held in mind. Speech-accompanying gestures open a window on the speaker's thought by providing "dynamic renditions of hypothesized conceptual relations translated into spatial configurations" (Mittelberg, 2010: 372). Critics relegating imagistic properties to an epiphenomenal, merely illustrative or emphatic status run into severe trouble. Landmark publications have shown that iconic properties of gestures genuinely reveal aspects of thought (McNeill, 1992, 2005; Kendon 2004; Cienki and Müller 2008; Streeck 2009; Stam and Ishino 2011; Calbris 2011). Since co-expressive gestures mesh with language in non-arbitrary ways they shed light on how speakers put thoughts into symbols, especially in relation to the on-line adjustments of iconic imagery to the available expressive devices of a language. Concerning its evidential value gesture stands in a line with research on multimodal metaphor in film, animation film, comic strips, visual advertising, and music (Forceville and Urios-Aparisi, 2009; Fahlenbrach, 2010; Forceville and Jeulink, 2011). Such data is complementary and in fact superior to verbal metaphor. As Forceville and Jeulink (2011: 39) point out, "a sustained focus on non-verbal and multimodal manifestations of conceptual metaphors is an essential way to further probe into the validity of CMT, if only because it leads away from the conceptlanguage loop", hence the objection that the verbal surface forms cannot conclusively shed light on the representational formats underlying language.

The virtues of gestural data are worth extolling first because visually displayed image schemas furnish greater argumentative leverage than verbal data. Nothing needs to be inferred through introspection. Iconicity, when ready-at-hand, is hard to explain away by those who think of language as disembodied or propositional. In this way multimodal approaches bolster experiments indicating that subjects instructed to characterize abstract referents readily choose image-schematic descriptors (Cienki, 2005) and related findings on abstraction in general (e.g. Casasanto, 2005). Secondly, co-speech gesture, by current consensus, is part-and-parcel of a multimodal information flow in which gestures complement speech and frequently "fill in" aspects that are not verbally expressed. As Mittelberg (2002: 1) puts it, "embodied aspects of abstract concepts surface in gestural metaphor in a way that depicts source domain information not necessarily captured by the concurrent linguistic expression". Hence, gestural data is ideal for learning about conceptual devices that may be little explicated in speech. Third and finally, co-speech gesture adds the great merit of holding two expressive channels in their dynamic relation in focus. I shall explain the gains involved in this later. 
M. Kimmel

\subsection{Defining structure-related / metanarrative gesture}

It is time to unpack an earlier assertion. Story structuration, whether at the producing or receiving end, belongs to a functional skill distinct from organizing content, although the two unfold in continuity or even dialectically. While both skills draw on similar imagistic mechanisms, we must not conflate these.

Turned into methodology this means that not just any kind of gesturally realized image schema may count as evidence for story structure. For instance, a PATH-INTERVAL gesture with several small chops along an imaginary line that maps to the overall temporal progression of a story qualifies for analysis, for it transcends the single scene level and refers to the structural relation between episodes. The same gesture used to tell about a caretaker slicing a strudel into five equal pieces for a group of children remains non-metaphorical, concrete, and scene-bound. Defined ex negativo we must therefore exclude gestures in conversational storytelling that support scene simulations in a nonmetaphorical function. By this I mean all quasi-perceptual gestural renditions of a narrow timeframe in the imagined storyworld (Herman, 2002). In such renditions the imageschematic structure is largely responsible for conveying who does what, where, and for what purpose (see Section 1). Gestures may thus foreground agents, actions and action affordances, objects/props, or settings by a variety of means: (a) hands that recreate an action from a specific scene such as shaking hands, kneading dough or sprinkling water, (b) hands or fingers that embody an agent or signify the spatial relation between agents in a scene, (c) line traces, or cupped hands that suggest a spatial layout of a room, an obstacle, or motion into a space, (d) drawing gestures that stylize the outlines of an object or person, (e) pointing gestures within a space already created that clarify where one is standing or moving, (f) single hand gestures that enact an agent's or an object's manner of motion.

The co-speech gesture in Figure 1 exemplifies such a scene-bound use. Here, the German literary critic Hellmuth Karasek discusses Murakami's novel South of the Border, West of the Sun, using an accentuated upward swoop of his right hand at one specific juncture. This gesture refers to the male protagonist's frantic pursuit of a woman through town (6: 10).

(1) sein ['erstes Ver'folgen] his first pursuit der wiedergefundenen ['Frau durch die ${ }^{\wedge}$ Stadt], of the found again woman through the town

Evidently, the gesture represents a storyworld action that Karasek invites us to envisage in its temporal quality, a sudden burst of force that sharply contrasts with the protagonist's inaction before. (Note however that the box shaped by the hands just before the swoop brings into play a cadre-like quality, a quasi-window on the scene of action which is more to the side of structure than content). Such gestural references to scene content in the storyworld, abundant as they may be, are excluded from the analysis. 
PJOS 5(2), 2013

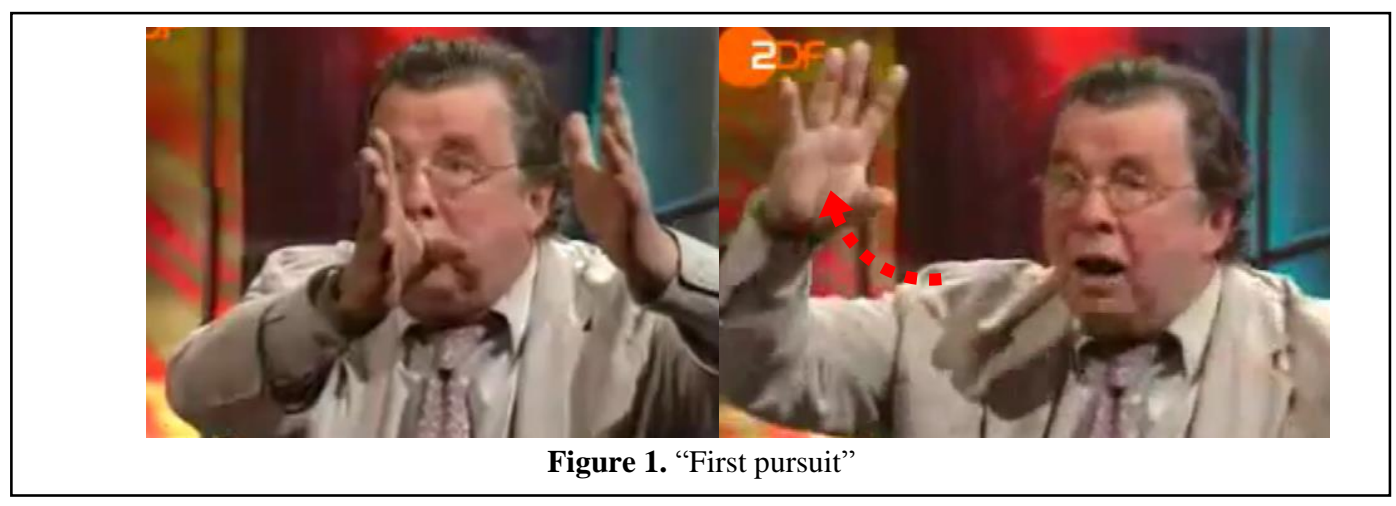

All gestures sampled in the following presentation pertain to metanarrative discourse, which I hold to include the story's macro-structural texture as well as summary (i.e. thematic) attributes of the plot. Here we may roughly follow the distinction between metanarrative, paranarrative, and narrative gestures proposed by McNeill (2005: 172). In metanarrative "[t]he narrator speaks within her role as official storyteller and makes a reference to the structure of the narration qua narration" (e.g. temporal, causal or topical structure). This is distinct from paranarrative: "The narrator steps out of her role as storyteller and speaks for herself, addressing the listener." It is equally distinct from the narrative level: "The narrator speaks within the storyteller role and refers to an event from the story". Thus, my task in pre-sampling the data was to discard all gestures with reference to scene-level actions, agents, props, or settings and all gestures addressing the listener or related to the interpersonal situation of storytelling. To be more precise, all metanarrative gestures with a referential meaning qualify for sampling, in this case such created at a metaphorical plane. So-called rhythmic beats are for the most part excluded from this definition, even when metanarrative. To explain further, Cassell and McNeill (1991) found that beats may signal a shift of discourse levels, e.g. a brief flick of the hand used to mark a moment where the storyteller changes his or her perspective, and can thus serve a metanarrative function. In standard cases, however, the beat is not a meaningful clue to a specific imagistic mental representation. The only allowable exception concerns cases where a beat coalesces with metaphorical, referential aspects. E.g. repeated beats in a line may be used to suggest INTERVALS on a PATH, thus superimposing the beat on the path image so as to further structure it. I propose to speak of iconically embedded beats.

Note that my topic also overlaps with gestural discourse organizers that serve to organize the theme or clarify the relations among aspects (McNeill, 1992). For example, thematic spaces may be organized as if they were spatially opposed, e.g. when one says "on the one hand" and "on the other hand", such that each space stands for one idea or topic (DIFFERENT CONTENT IS DIFFERENT LOCATION). A speaker may also create a discourse space with her hands, thus conceiving a topic as a bounded space (TOPICS ARE CONTAINERS).

After the data sampling is done, we get a set of drawing/tracing, object shaping, and object representing gestures with non-concrete reference, some pointing gestures within abstract "theme-spaces" (abstract deictics), and perhaps an occasional PATHembedded beat. Now our analytic gaze moves to each gesture's (a) topological aspects, e.g. if it represents planes and spaces, or traces a path, (b) to relative positions of items in the visual field, e.g. spatial overlap, and (c) to gestural animation, e.g. kinetic crescendo. Expressed in the parlance of metaphor theory any such gestural property may come to 
visually display the source domain of a metaphor. The (metanarrative) target domain, in contrast, needs to be inferred. ${ }^{6}$ Consider, for instance, someone relating a story event while projecting an imaginary line with hands and gaze, and then proceeding to chop this line into elements or to pinpoint spots on it with one index finger. If the spoken words foreground a sequential event, every culturally competent adult will infer that the gesturally traced line represents an abstract timeline and that the chops and pinpoints refer to PARTS in a WHOLE located on this temporal PATH, thus adducing in their minds a set of related metanarrative target domains.

To anticipate an obvious question: Not every dynamic topology in gesture is mainly or only image-schematic. ${ }^{7}$ Richer mimetic schemas are at least as common, in which the hands mimic a highly specific action like hitting, turning a screw, or pinching (Cienki 2013), and which tend to be the first iconic gestures mastered, as a study of Swedish and Thai children suggests (Zlatev, in press). If mimetic gestures play little role in my present analysis the reason is evident. The highly abstract target of metanarrative simply favors image schemas. Inversely, mimetic schemas tend to relate to actions at the narrative or paranarrative levels. Note however that mimetic looking gestures should not be discarded out of hand. Image schemas may be embedded in a mimetic substrate, e.g. hitting can have a PATH to it, screw-turning a CIRCULAR PATH, and pinching APPROXIMATION and CONTACT. An object holding gesture does not automatically imply an instance of object handling; it might equally express the abstract idea of boundedness.

\subsection{Notes on method}

The analysis starts from a semantically loaded and metaphorical gesture that a native speaker has little trouble making sense of in context. The researcher's task is now to explicate what the recipient's cognitive unconscious has to fill in to endow the gesture with metanarrative meaning. Any gesture needs to be analyzed holistically with the speech that it accompanies. There are two reasons for this. First, metanarrative status is nothing that attaches to a specific external form. Only context tells us if a hand's linear shift is a path a protagonist runs along or an abstract timeline. Metanarrativity is indicated when other levels of meaning seem unlikely or certain aspects of the gesture do not fit with scene content.

Second, deciding what a metanarrative gesture specifically stands for, say a target domain such as "scene structure", "main motif" or "act of storytelling", is subject to its interaction with speech. In the ideal, but infrequent case the gesture mirrors metanarrative speech itself. More often precise verbal counterparts are missing, so that the metanarrative meaning must be inferred. While the words - especially those uttered during the stroke phase of the gesture - continue to provide meaning anchors, the target domain is only signaled by the holistic co-text or implied context.

To be sure, some "usual suspects" in speech act as pointers to metanarrative meaning. Speakers express causal coherence links through "because", "so" or "consequently", temporal links through "then", "in the meantime", or "earlier", scope through "generally", "here", and "for the most part", thematic links through "by contrast" or "notably", and causal-intentional or evaluative hedges through "somehow",

\footnotetext{
${ }^{6}$ Note that gestures that express a metaphor's target, while occurring elsewhere, are logically impossible in the case of abstract story structure.

${ }^{7}$ In fact, the precise status of the notion of image schema has been debated with respect to schematicity, contextuality, and the forming of compound structures that configure elements in a schematic scene (Hampe, 2005, notably Kimmel, 2005a, as well as Kimmel, 2008a).
} 
PJOS 5(2), 2013

"indirectly", "ultimately", and "seemingly". Being sensitive to verb aspect is also helpful. Finally, prior knowledge about frequent conceptual metaphors can prove an asset for locating metanarrative gestures, but cannot be chiefly relied on without running the risk of circular reasoning.

The data to be scrutinized comes from shows that present and comment on newly appeared novels to a German TV and internet audience. I chose two literary critics who gesture expressively and copiously even in relatively short discourse sequences. I deliberately sampled a discourse genre with high "compression factor", which arguably ensures a high frequency of gestures organizing narrative discourse qua narration. In the far more detailed re-telling of a TV-cartoon studied by Cassell and McNeill (1991: 397) metanarrative gestures constitute less than a third of all tokens, whereas in my summarizing corpus they predominate. Being partly due to the speakers' proclivities, this fact clearly also owes to the chosen discourse genre of literary commentaries. These lend themselves to frequent metanarrative gesturing: First, being summarizing in nature they involve a much lower proportion of micro-structural gestures (actions, objects, settings, etc.). Second, commentaries are challenging. To sum up the gist of a novel within a few minutes one needs to envisage complex shifts and interconnections between its parts, which in turn requires the strategic use of structuration devices - such as metanarrative gesture!

\subsection{Storyteller One}

As the aim is not a quantitative study, I have simply culled examples from the corpus, the full transcripts and gesture descriptions of which appear in the Appendix. (Note that "/" separates intonation phrases here instead of separate lines). One set of examples comes from the TV-format Literarisches Quartett (= literary quartet, a series which ran between 1988 and 2001) in which novels are presented in 15-minute-slots and discussed by four literary critics. One of them always summarizes and evaluates the novel, before the others respond. In the following extended sequence Hellmuth Karasek summarizes Murakami's previously mentioned novel, producing several gestures.

The gesture in Example 2 (0:58 [=timestamp]) uses a multiple vertical shake of the half opened palms, as if weighing an object. It occurs while Karasek is relating the novel's first key scene, in which the main protagonist meets his puppy love after ages.

und [er 'trifft seine 'erste ${ }^{\wedge}$ Liebe],

and he meets his first love

A storyworld related interpretation makes no sense here, because the gesture's shape depicts neither the act of meeting nor other aspects of the concrete scene. By contrast, metanarrative meaning literally jumps at us. The extended gestural stroke phase appears with the description of this incisive event and foregrounds qua episode in accordance with its role of setting all that comes in motion. The hands form a kind of container-like shape before the body, presenting the scene of the encounter as something bounded. This invites us to think of this occurrence as thematically, spatially, or temporally circumscribed and as having specific properties. Depending on emphasis we can metaphorically interpret it both as SCENES ARE CONTAINERS (FOR PARTS) and as THEMATIC COHERENCE IS PHYSICAL COHERENCE OF A DISCRETE OBJECT. This hold is performed while Karasek describes the inner richness of the scene, so if ideas about it are thought of as objects in a container this privileges the first reading. 
Two other aspects of the gesture carry meaning, with a possible, but debatable metanarrative status: The increased kinetic energy of the gesture metadiscursively signals its heightened importance. The encounter's intensity and incisiveness is also foregrounded in prosody and volume. This contrasts with the surrounding story background, which lacks emphasis in voice or gesture. In a sense, a feature particular to this scene, namely the protagonist's agitation, spills over to Karasek's own excitement. Second and related, further meaning accrues from the iterative aspect of the vertical shake, which marks a specific juncture in the narration by lingering there for some time. Under a conventional reading, repeated images or words are simply used "to drive a point home". Under an imagistic reading, however, the fact that the story-flow is slowed down and continuation has to wait creates a quasi-filmic effect. Gestural iterativity is almost as if we hit the replay button on our video player to stay with a scene for detailed inspection instead of letting the prior narrative tempo run its course. Emphatic holds imply a kind of gestural "freeze-frame" (cf. Arnheim, 1969). ${ }^{8}$ When we focus not on the beats per se, but the scene-container's multiple presentation that is interspersed by beats, i.e. iterativity as such, this element arguably augments the container's metaphorical meaning.

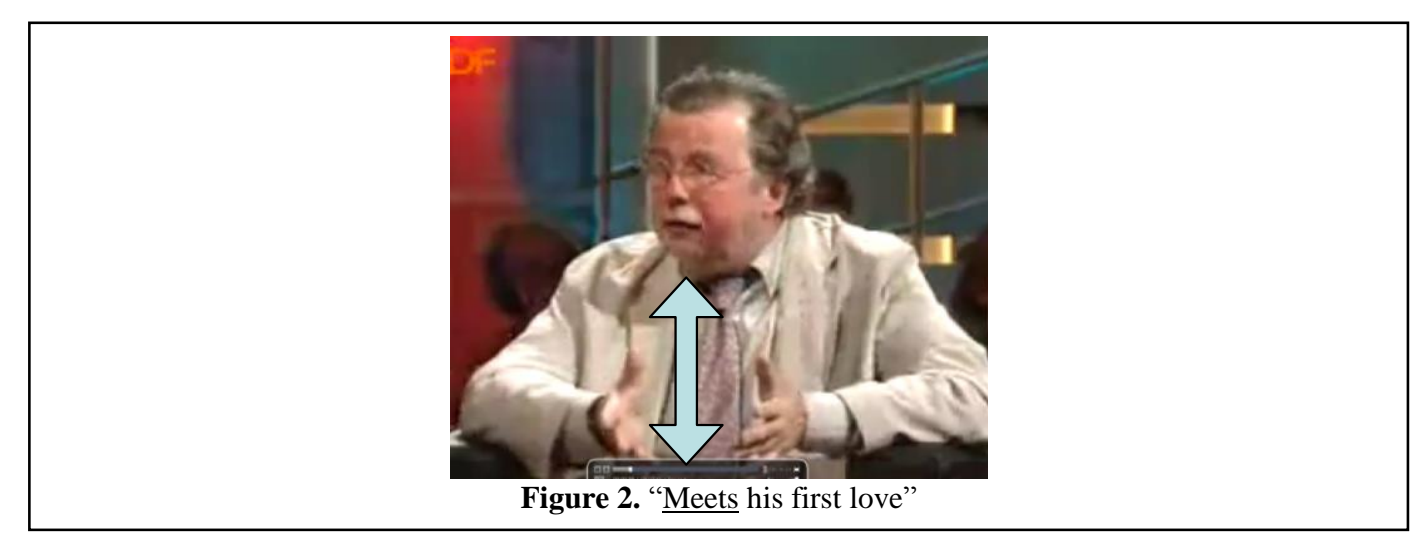

In Example 3 Karasek uses two distinct gestural strokes with a half open hand presenting an imaginary object while he verbally summarizes what he thinks constitutes the story's deeper relevance, namely an encounter with death and chaos (1:33).

(3) ist auch eine ‘Art Be ${ }^{\wedge}$ gegnung, / [mit dem $\left.{ }^{\wedge} \mathrm{Tod}\right], /$ [mit dem $\left.{ }^{\wedge} \mathrm{Chaos}\right]$. is also a kind of encounter with the death, with the chaos

The repeated presentation gesture suggests two thematic objects, death and chaos, and precisely co-occurs with these two spoken words. The gesture accentuates death and chaos as separate, but equally important key themes. Topical separateness is signaled through different hand positions in the gesture space, with the hand dropping briefly before resuming for the second topic. This holding/presenting gesture has embedded image-schematic features, notably semi-boundedness and suggests the mapping STORY

\footnotetext{
${ }^{8}$ The gesture might implicitly make us fill in the mapping STORY EVENTS ARE POINTS/INTERVALS ON A NARRATIONAL PATH and thereby think of the scene as foregrounded against a wider imagistic backdrop. Considering the present case in isolation, this claim would circularly assume what the argument purports to show. However, other data suggests that the interval gesture standing for time progression is fairly conventional, as Figures 11 and 14 below indicate. Outside our sample I have also seen a shifting window on a timeline signaled with a thumb and index finger pinch.
} 
PJOS 5(2), 2013

THEMES ARE OBJECTS. Another possible meaning of a more evaluative sort lies in the fact that the two strokes are equally energetic, i.e. IMPORTANCE IS FORCE INTENSITY.

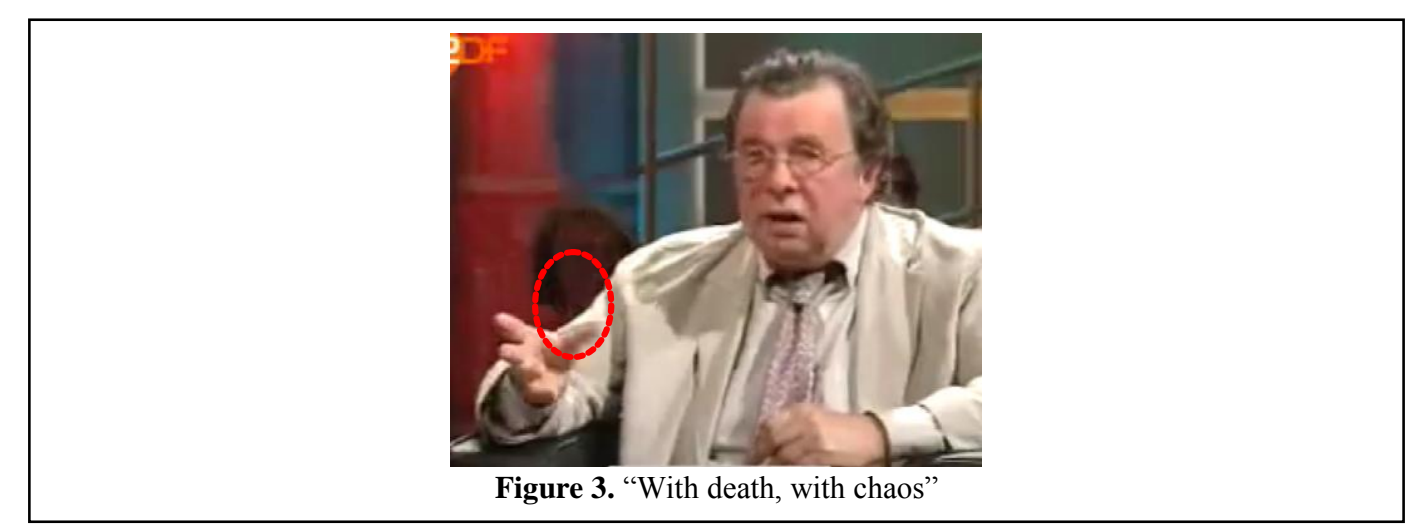

Karasek's gesture in Example 4 summarizes different story motifs (1:59).

(4) [weil die 'Kriminal'motive verlaufen alle ${ }^{\wedge}$ blind] ins 'Leere because the crime motifs run all blindly into the void

After having suggested some initial likeness of Murakami to Raymond Chandler, Karasek states that these crime story motifs run blindly into the void while producing an upward sweeping, accelerating, and finally dispersive gesture. The words and the gesture together designate the top area as "the void". By implying that Murakami follows a path-like subnarration, Karasek creates the mapping STORY THEMES/MOTIFS ARE PATHS, perhaps a derivative of STORYTELLING IS MOVING ON A PATH and related to the conventional "line of reasoning" and "storyline" metaphors. The gesture implies that a continued motif would require a continued path, whereas the actual upwards and outwards swing of the opening hands suggest dispersal and evaporation into the surrounding space. This idea is conveyed by the decreased kinetic energy and finger relaxation towards the end of the hand's fanning out, i.e. a lessening of intensity.

Our last two examples have moved into focus how storytellers ontologize themes, motifs, and summary attributes (cf. Example 10, where the same happens with a stylistic summary attributes). Before we continue with the next of Karasek's gestures, let me expand on this topic. Conceivably, the speaker might also organize thematic relations by "picking out" a particularly important aspect with a pinching gesture (THEME SELECTION IS OBJECT SELECTION) or by expressing qualitative differences in ontology through spatial location (DIFFERENT IS APART). In Cassell and McNeill's study of a Hitchcock film (1991: 399), the narrator uses the distance between the left and frontal gesture space to emphasize a sharp dichotomy between true and apparent morality, in contrasting who is assumed to be, and who really is the killer. ${ }^{9}$

\footnotetext{
${ }^{9}$ To speculate further, theme attributes might be implicitly thought of as instantiating what I call a quality space ICM in Kimmel (2002). The idea is that gestural containers may collect story attributes expressed in speech and iconically present to our attention the essence of the story. A critic might, for instance, verbally attribute a sensuous and avantgardistic nature to a novel while performing a container gesture to which these attributes belong (see Cienki, 2008: 16f.). A quality space depends on the container-related OBJECT image schema and exploits one of its experiential aspects. Solid objects are typically made of homogeneous substance. The inner part of a stone or a slab of wood defines its characteristics, e.g. texture, brittleness, or
} 


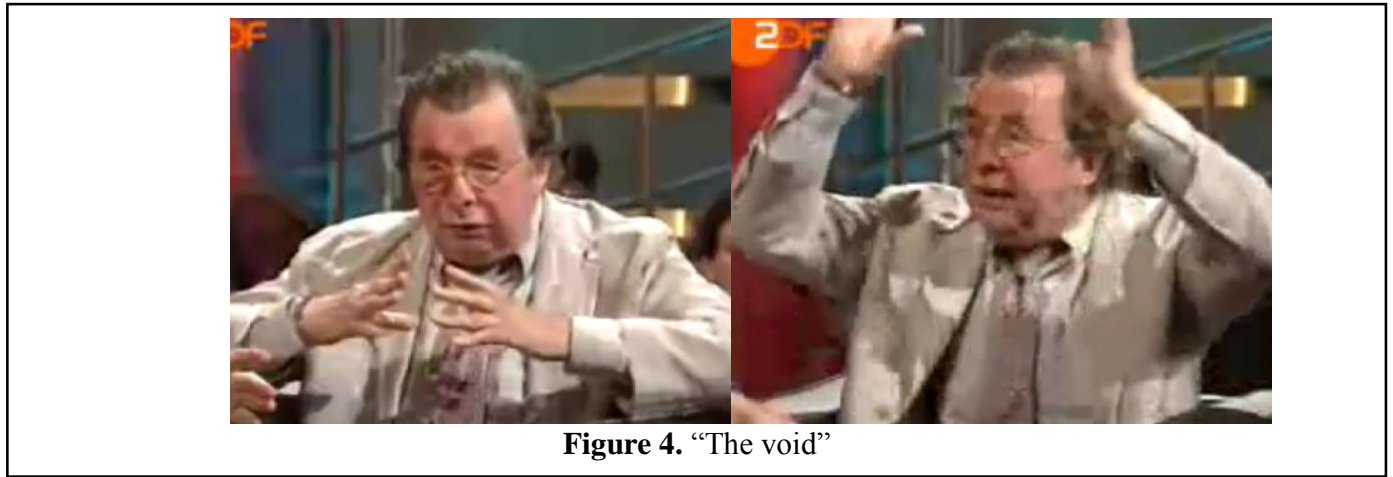

In Example 5, Karasek contrasts the evidential status of a scene in which the protagonist is uncertain about how to evaluate his love experience (6:23).

(5) uns [im ^Zweifel] zu lassen / ob das das [^real] oder [er'träumte] Szene ist us in the doubt to leave whether this-this real or dreamt up scene is

So the author keeps us in doubt about whether these are real or dreamt scenes. We have here two metanarrative gestures of a thematic kind which summarize the scene attribute of the protagonist's perplexity. In the first intonation phrase (no figure) Karasek's slightly cupped hand and closed fingers quickly oscillate four or five times, thus mapping semantically onto the synchronized expression in doubt (UNCERTAINTY IS WAVERING). The hand then freezes for a split-second while saying real scenes, only to shift forward by two inches or so with the words or dreamt scenes (Figure 5). From this point on the tiers expressed by the first and second hand positions apparently refer to the ontological difference between dream and reality. Gesticulation indicates that these two distinct realms of experience are being construed as planes, while the verbal or and the hand's quick shift in sync with this word imply that Karasek additionally thinks of these realms as standing apart (EXPERIENTIAL REALMS ARE PLANES; DIFFERENT IS APART). Two meanings are thus laminated and synthetically expressed.

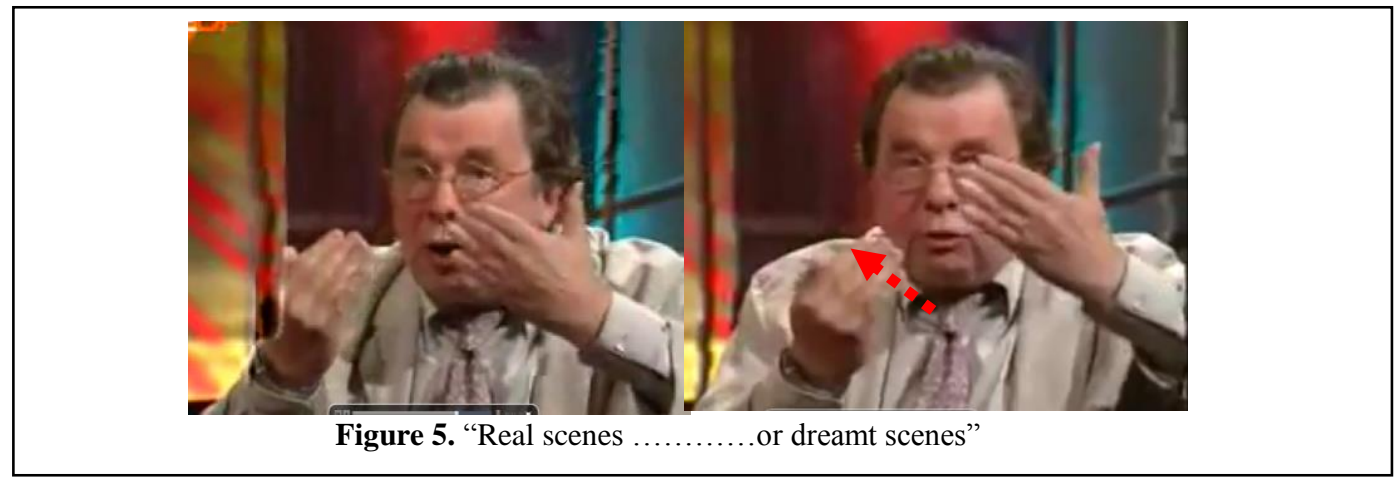

In Example 6, Karasek summarizes Schiller's play Wallenstein. The context is that the warlord Wallenstein leads his war because the German Emperor has disappointed him. In

hardness. Our embodied dealing with substances may thus form an experiential basis for abstractly representing "essential" attributes. The object's essence comes about by virtue of its inner substance which defines it as being of a certain kind, even if the specific nature of the substance remains unknown! 
PJOS 5(2), 2013

this particular gesture Karasek emphasizes an all-important causal link through a pointed finger which traces an arc from the rightmost position to the middle (4:11).

(6) ['weil der ${ }^{\wedge}$ Kai] $]$ ser ihn, / sozu'sagen ent[^täuscht hat], because the Emperor him so-to-speak disappointed has

The gesture stroke begins right at the prosodically emphasized because and the pointed finger reaches the lowest point right before as it were. Then a very brief pause with a miniature beat follows. As the main sentence resumes with the word disappointed, Karasek repeats the arc in a smaller, incomplete way, so as if to reinforce his meaning. Evidently, both arcs signify "one event leads to another", as cued by the word because. They link a cause, the starting point, to a result, the end point (STORY EVENTS ARE POINTS IN SPACE/ CAUSALITY IS A PATH BETWEEN THEM, CAUSALITY IS FORCE TRANSFER). Alternatively, it might be read as A CONCLUSION IS A PATH END-POINT if we emphasize the argument made by Karasek himself, rather than Wallenstein's perspective. The decisiveness conveyed by the vigorous gesture throws into relief Wallenstein's very compelling motives. Had it been Hamlet's indecision, a typical case of "may or may not", we might have instead seen wavering kinetics, a frozen, slowed down, or interrupted-andresumed arc. This would reflect Sweetser's abovementioned work on modality. When modality is encoded in the manner of motion, tentative gestures stand for may, decisive ones for must, and free muscle flow or unrestrained micro-movements for can.

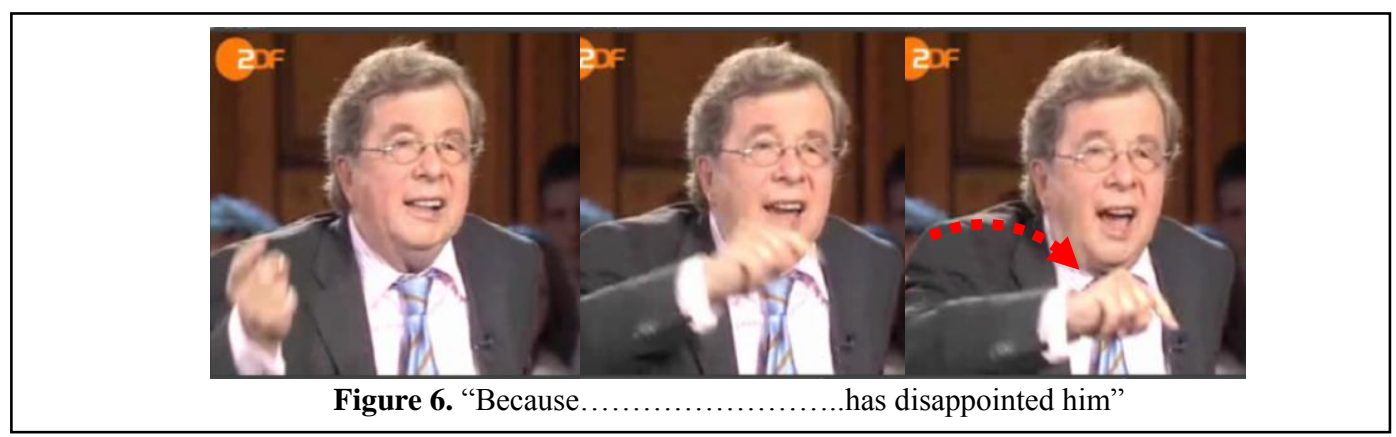

\subsection{Storyteller Two}

I will now turn to Roger Willemsen, a popular showmaster who presents 3-5 minute book recommendations in his web-based format Willemsens Bücher (= Willemsen's books). Let us begin with his presentation of Hamsun's Mysteries a narrative of a man who spontaneously stops by in a city and causes all kinds of confusion (2:15).

(7) $\quad$ er 'richtet eine $[\wedge$ Menge von Ver'wirrungen $]$ an.

$$
\text { he creates a lot of confusion [part of verb] }
$$

['einmal kommt sogar] eine ${ }^{\wedge}$ Frau und besucht ihn, once comes even a woman and visits him

['aber das ist] nicht ${ }^{\wedge}$ wichtig.

but that is not important 
The gesture sequence begins with two counter-rotating hands that give iconic substance to the idea of confusion (no figure), but the metanarrative gesture I wish to mainly focus on morphs directly out of the former. Now, while uttering once, even a woman appears Willemsen swipes both upwards facing palms from the central gesture space to his right side. As soon as the earlier counter-rotation discontinues, the two hands switch to a stable equidistant orientation and now suggest a semi-bounded, slightly cadre-like space. Next, the words but that is not important occur in sync with his bringing both hands to the other side, the lower right-hand quadrant of the gesture space. A relaxed wiping motion of the right downward-rotating palm is also noticeable. Although the equidistance and the cadre are weakened, a hint of a semi-bounded space on the left hand side remains.

Let us first look at the global phase dynamics in this example. Two metanarrative readings suggest themselves. The right-left switch clearly instantiates the generic "on the one hand - on the other hand" gesture which mirrors Willemsen's verbal but and is synchronized with it (DIFFERENT IS APART/OPPOSED). Rather compatibly, the switching of sides and especially the wiping motion may also be interpreted as "setting this aside". Next, the middle phrase once... appears deserves closer inspection. The almost cadre-like hands visualize the focalized episode as a bounded space, suggesting the mapping SCENES ARE SPACES or SCENES ARE CONTAINERS. Although the hands might not be enormously rigid or straight in absolute terms, the recipient will probably invest even the weak gestural boundary with meaning. After all, the hands became visibly tenser the very moment that Willemsen morphed his previous gesture into this one. This sudden change is too obviously synchronized with the word once, which cues a temporal re-focalization to a more granular episode level, to escape notice. Hence, speech-tension synchrony and the new focus in the gesture space together make us pick out a metaphorical scene from the gestural flow. Lastly, when the hands wander to the left speech itself suggests that the scene boundaries are no longer in focus; instead a meta-evaluation follows $($ but ... $){ }^{10}$

Incidentally and moving away from my material for a moment, episode units construed as containers can be put to interesting dynamic uses. Cassell and McNeill (1991) report a speaker who retells a scene fade-out from a Hitchcock film by clenching a hand, as if it were the end of a film shot that lets the scene shrink to a spot before disappearing.

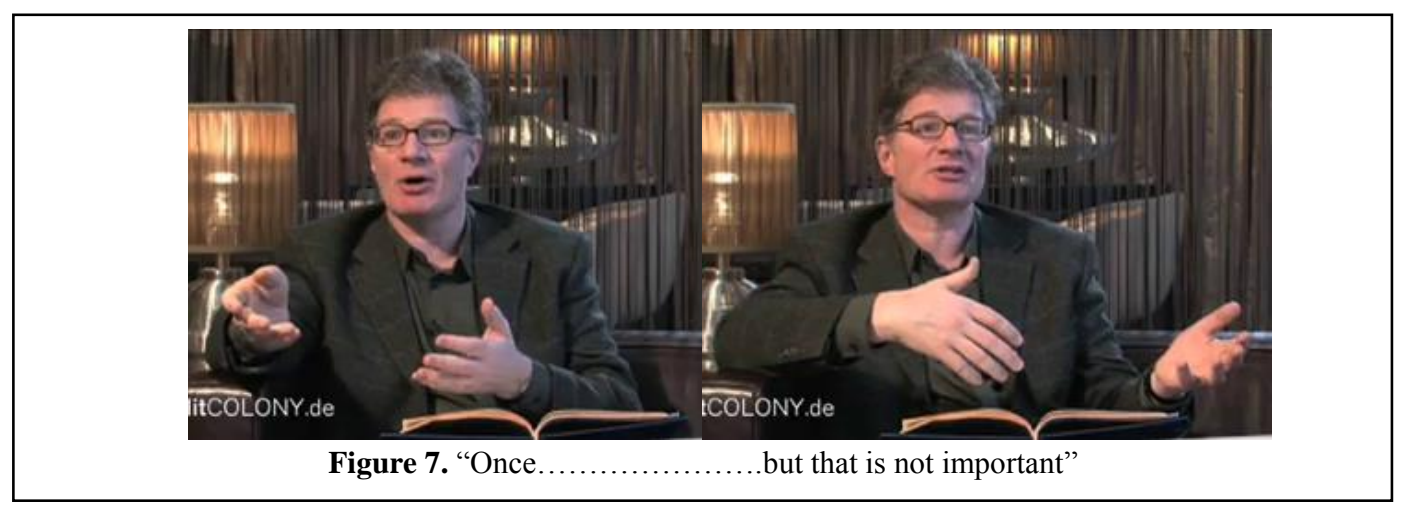

\footnotetext{
${ }^{10}$ Of course we might just as well have found a passage in which the speech relates a second scene in similar detail and fully recreates the cadre at the left to stand for the former. This gesture, which I have often seen elsewhere, would ostensibly contrast two scenes with respect to their main theme.
} 
PJOS 5(2), 2013

We now move to a semi-biographic book about the theater director Peymann written by Hans-Dieter Schütt (1:40). Willemsen comments as follows:

(8) [bei 'all diesen]^Ausschnitten, / [die 'unter'schiedlich be]^lastbar sind, with all these extracts which differently loadable are

die manchmal ['rein] amü^sant sind, / [die oft] [über^rasch]end sind, which sometimes purely amusing are, which often surprising are

The idea is that scenes from Peymann's life are variously pliant or filled with implications; we don't really know which of these two meanings Willemsen had in mind. Let us look at the second to fifth stroke phases and their metanarrative meaning. Willemsen starts by fanning out both planar hands at slightly different horizontal levels with three small, quick dabs of each hand during the word differently (DIFFERENCE IS VERTICAL DISTANCE). Each of the lined up dabs apparently refers back to one of the story "extracts" mentioned a split second earlier (THEMES/SCENES ARE [HORIZONTAL] LOCATIONS). Next, during the word loadable the right hand drops by a centimeter, while its orientation suggests a horizontal surface pressed down by a load. The overall implication now is IMPORTANCE IS PHYSICAL WEIGHT. Then, with the attribute purely amusing, Willemsen repeats - and semantically continues - the two tier gesture, this time with added vertical distance to represent the difference between amusing and serious content. Finally, with the words which are often surprising he lets his right hand go into a slightly vibrating planar motion. This possibly represents the titillating quality of surprise. It seems as though his hand metonymically expressed the rhythmical somatic quality we usually associate with felt surprise.

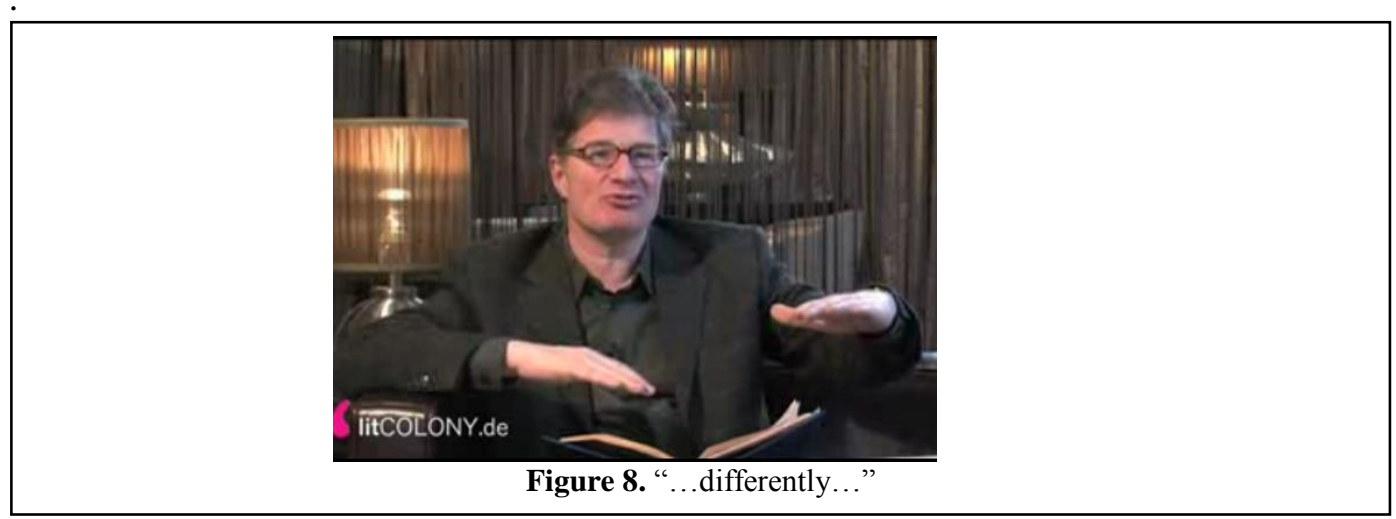

A complex of gestures relating to activity over time occurs in a discussion of Bouvier's Scorpion Fish (1: 34).

(9) [und 'hat] $\wedge^{\wedge}$ jetzt, / inspirat['ive ${ }^{\wedge}$ Schübe], / ['dann und 'wann hat er=n] ${ }^{\wedge}$ Einfall, and has now inspirational thrusts occasionally has he an idea

Bouvier recounts his travels in a state of sickness and Willemsen focuses on the inspirational thrusts this gives him. We begin with the second stroke phase. A quick semicircular motion of both half opened hands, performed almost as if he recoiled to generate impetus and then pushed a mass slightly downward and forward, maps perfectly on the 
force related word thrusts, as does prosody. After a brief pause, the same gesture is repeated as he begins to say occasionally he has an idea. In both gestures the author's best inspirations are metaphorically represented by energetic and concentrated motion, ostensibly against a baseline of normal storytelling with less energy. Verbal and gestural force cues, when combined, suggest the mapping Bouvier's AUTHORIAL CREATIVITY IS PHYSICAL EFFORT. What is more, Willemsen employs his own timing to say something about temporal structure in the novel. The phasic distribution of the concentrated thrusts in his actual discourse time map onto bursts of activity interspersed by less active phases in the evoked story. In other words, the temporal features of Willemsen's synced speech and gestures are meant to iconically replicate the process dynamics either of Bouvier's storyworld or even his storytelling pace. We may infer the mapping GREAT STORY(TELLING) ACTIVITY IS HIGH ENERGY.

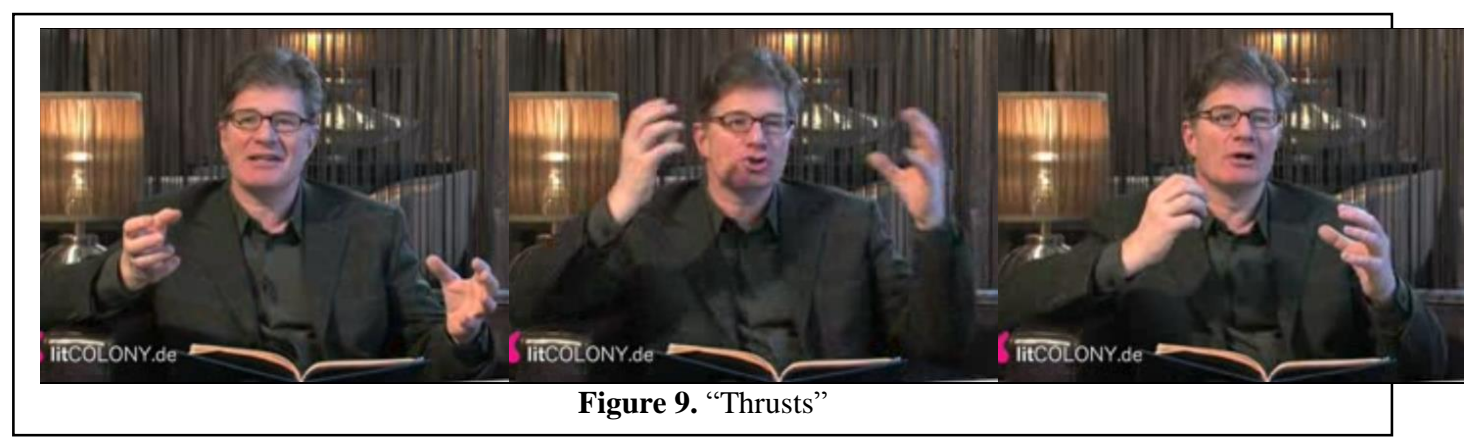

Let us see how the same passage continues (1:38).

(10) 'dann und 'wann [^kommt],/[n 'lyrisches] Frag^ment, occasionally comes a lyric fragment

Willemsen shapes a three-dimensional ball in center position to designate the lyric fragment. To do so, he has to morph his hands from the previous straighter position in the central gesture space into a both-handed twisting motion. It is almost as if molding a snowball or assessing the texture of an apple through repetitive micro-movements. The tactile appraisal is subtle but potentially highly meaningful. Since lyric refers to a literary style and fragment to a passage from the novel, the gesture's spacing and shaping together suggest STYLES ARE TEXTURES and, again, SCENES ARE CONTAINERS/BOUNDED SPACES. I would think that the textural meaning here is a derivative of a more generic mapping that can pertain to abstract attributes of more or less anything. 
PJOS 5(2), 2013

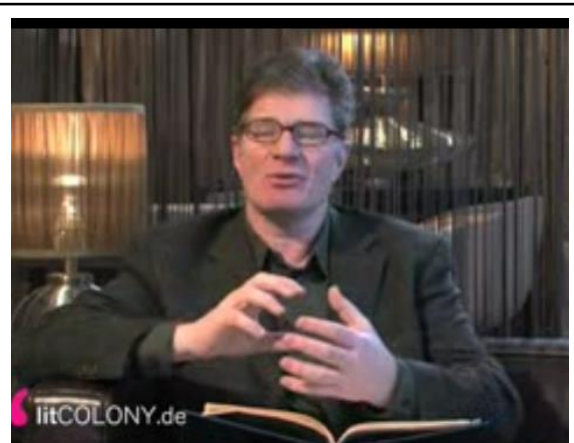

Figure 10. "Lyric"

The last example from the same passage about Bouvier reads as follows (1:39).

(11) ['dann und 'wann ^geht,] / [ne 'un]mittelbare ${ }^{\wedge}$ Wahrnehmung, / [^über,] occasionally goes an immediate perception over

[in ne 'Existenz $]^{\wedge}$ Stimmung.

into an existence mood

Gesturally, Willemsen continues into an arc-like motion from left to right with his still object-holding, but now more distant hands, while saying that every now and then immediate perceptions pass over into an existential mood. His gaze and both his hands shoot forward by a few centimeters precisely with the phrase immediate perception. Possibly, the forward motion depicts sensory immediacy iconically, understood as Willemsen's own path towards a perceptual object or as bringing it closer to the audience. However, as I am uncertain whether this is metanarrative, my main present focus lies on how the gestural arc replicates the spoken metaphor "passes over into". The gesture dynamically moves through three distinct locations, a beginning, a middle part with a brief hold, and an end-point. The middle space is held as Willemsen emphatically uses the word über (over) from the German (geht...über = 'passes over into') to emphasize the boundary between the two spaces. The dotted lines in Figure 11 represent this transitional phase. Apparently, the bounded space between the hands maps onto the verbal topic of the protagonist's inner states (or by implication the reader's). Both the word into and the bounded-space gesture ontologize these as (EXPERIENTIAL) STATES ARE CONTAINERS. Furthermore, the arc trajectory in its entirety foregrounds the processual nature of Bouvier's story(telling) as CHANGES OF STATE ARE A PATH. It represents a series of consecutive container-like snapshots. This makes the recipient think of a process of dynamic transitions in experience or mood. The trajectory gesturally represents change as such, as indicated by the three different positions on the arc. When we also look at Willemsen's timing more closely, gradual rather than abrupt transitions are implied, i.e. GRADUAL CHANGES ARE GRADUAL MOTION. Again, the speaker's synchronized speech and gesture dynamics iconically imitate how story time unfolds. 


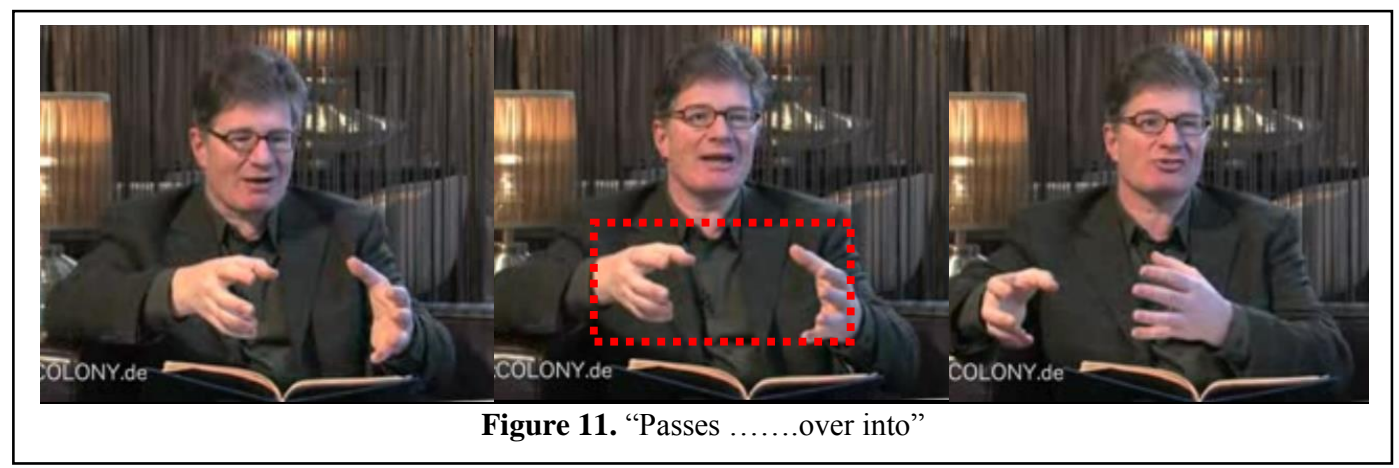

Moving to Svevo's Una vita we see a gesture with image-schematic significance, besides being manifestly mimetic at the surface (1: 16).

(12) in denen [^sämtliche 'Fäden] des 'Romans, / 'durch^schnitten werden in which all threads of the novel through-cut get

Willemsen speaks about an insert in the middle of the book in which all threads of the novel are cut while mimicking a snipping scissors with two fingers. The spoken metaphor thread seems to be a concretized instantiation of the image-schematic TOPICS ARE PATHS mapping which we have seen in Karasek's fanning out gesture in Figure 4. Since words and gesture, when applied to the target domain, suggest a causal discontinuity they might tie in with the "billiard ball" model discussed in 2.3 - as a broken force chain. Although the image of a thread primarily focalizes spatial extension and not an actual motion trajectory, the recipient is prone to dynamize this mental image by scanning the thread and stopping at the cut (cf. fictive motion, Talmy 2000).

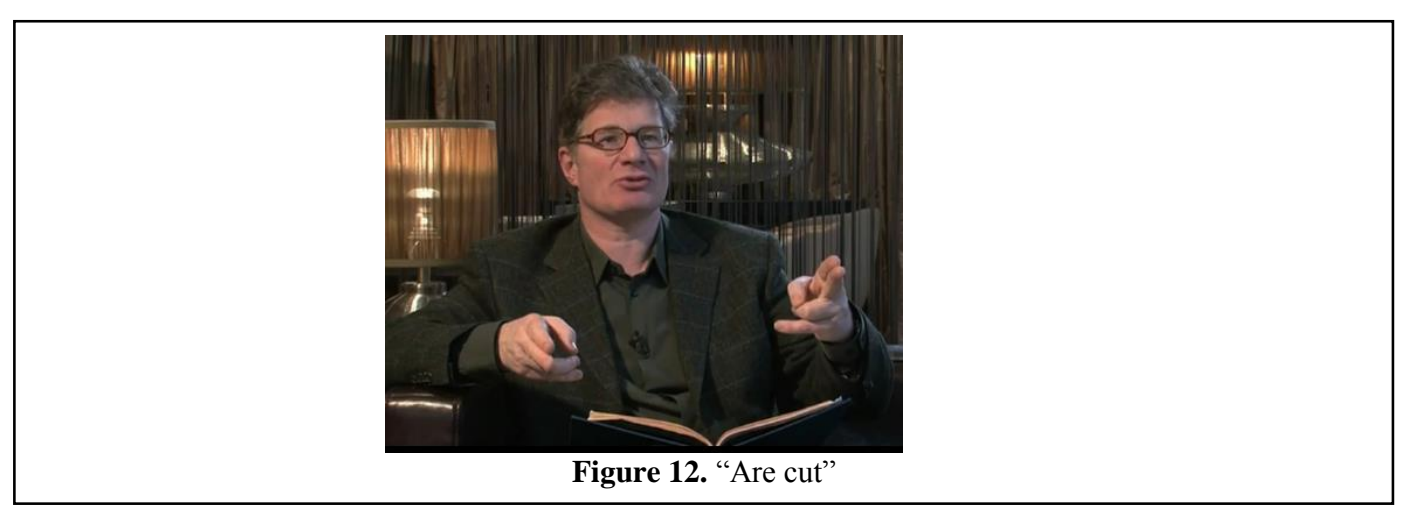

Willemsen continues by describing a major thematic shift in Svevo's novel (1:17).

(13) und wir [plötzlich ^ganz] isol'iert, / ['einen ^Sohn,] and we suddenly wholly isolated a son

am ['Sterbebett der ${ }^{\wedge}$ Mutter] er'leben, at the deathbed of the mother experience 
PJOS 5(2), 2013

The author suddenly shows the reader an isolated experience of a son at his mother's deathbed. In sync with the words wholly isolated both forward pointing palms turn rigid, thus delineating a left and right margin. They remain in this position throughout five beats which emphasize the rest of the sentence. While the words depict this scene as discontinuous with the rest of the novel, hence as a thematic insert, the gesture adds to this by offering a well-delineated metaphorical space for the insert. Speech and gesture together amalgamate the mappings A THEME IS A CONTAINER and A SCENE IS A CONTAINER, with the verbal explanation of the scene content "filling in" the theme into the bounded space, which can be thought of expressing an abstract time unit. Note also that the rigid palms might imagistically reinforce the separating cut from Figure 12, which initiates the assertion of topical or causal discontinuity with the rest of the novel.

While zooming in on the episode, Willemsen also clarifies how this part relates to the story's whole. To speculate a bit further along these lines, a NESTING hierarchy between episode and main plot might be suggested. The image of embedded levels would nicely coalesce with the scene-container image if understood relative to the common knowledge that stories are made of multiple episodes, whereby each scene will be interpreted as PART of a WHOLE (possibly with superordinate story goals to be resumed later, see Section 2). Note finally that the idea of isolation cued in words and gesture alike, is quite possibly redoubled at the content level to refer to the son's emotional feelings of isolation at the deathbed. The sentence's phrasing leaves open how the word isolated was meant by Willemsen.

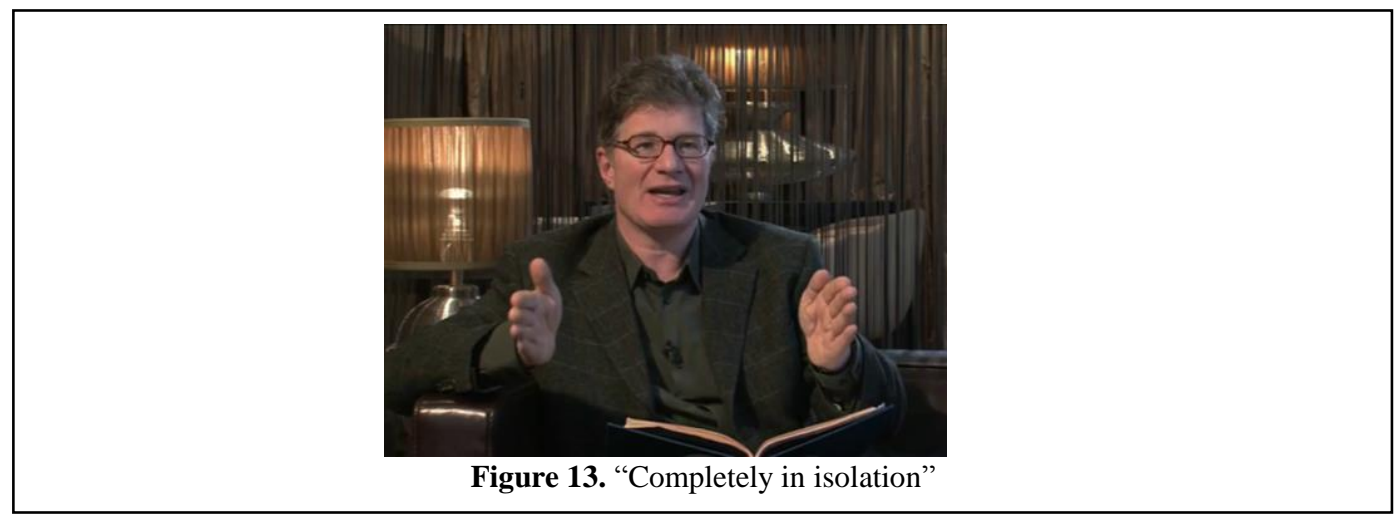

The sentence still continues (1:20).

(14) [in einem] ['la:ngen Pro'zess der Ago^nie.]

in a long process of agony

[=und erst als 'dieser] ${ }^{\wedge}$ abge‘schlossen ist, $/\left[{ }^{\wedge}\right.$ setzt der 'Roman] wieder 'ein. and only when this completed is sets the novel again in

The lengthened word itself indicates the lo-o-o-ng process which must end before the main thread of the novel resumes, i.e. with a new episode of the main plot. Starting from the position shown in Figure 13, a tripartite gesture is created that follows an imaginary timeline from left to right and segments it. This gesture unfolds in exact synchrony with the intonation units and begins as Willemsen brings both forward pointing palms together in the left lower quadrant while saying in a. With the next words long process the right hand begins to glide towards the right and with agony he reaches the end point in the 
right lower quadrant. Next, with only when this has ended the left hand begins to move towards the right one and rejoins it to signal that the process is coming to a close. Finally, the right hand begins a new path segment where the first one just ended with the words the novel resumes. Over all three phases verbal and gestural timing are in perfect sync. At the level of metanarrative meaning, the gesture's linear path structure stands for temporal extension, whereas the continuous movement between the intervals signals a steady process. More precisely, causal sequentiality is highlighted. One process is contingent upon the completion of the one before it. The fact that the hands meet only to begin again indicates that one process follows directly upon the other. One starts where the other ends. (TIME UNITS ARE PATHS, CONSECUTIVE TIME UNITS ARE ADJACENT PATH SEGMENTS, DISCONTINUATION IS REACHING AN END-POINT). An interesting detail emphasizes this causal continuity: At each point the static hand is the relational anchor for the hand in motion, with the hands switching roles the moment the first hand has reached its end-position ( $=$ dotted arrow). In addition, we may note that all three hand movements trace a slight, but noticeable arc, in which the lower positions signify the beginning and end-points; a sort of BEGINNING IS UP, FINALIZING IS DOWN.

To recap all temporality-related gestural data, events and scenes are points or containers on a path which may be chunked and segments picked out for focalization. The specific manner in which a trajectory is gestured may also highlight features of the timeflow such as gradualness or extension, as in the example l-o-o-o-ng. Furthermore, speakers can alternatively foreground the process or the result by employing heightened dynamics or by freezing a gesture (Müller, 2000: 218f.). Before I continue let me address some added complexities, with some leeway for speculative extension. In non-linear story renditions gesturing is useful to off-load the tracking task onto the visible material signifiers in the gesture space. This helps speakers and recipients keep track of discourse vs. story time (see Section 2). Thus, performing a flashback becomes backtracking on a previously established timeline and when speakers thematically interrelate points in the story this becomes pointing to the timeline. More generally, the temporal discourse PATH may be broken up into INTERVALS and re-mapped onto a second PATH in a mental space representing the logico-causal story structure. Finally, in view of the time-honored mnemonic method of loci I would not be surprised by storytellers who think of story time as an extended area or line which one can zoom in on, so as to foreground an episode before resuming the overview again. If indeed perspectival zoom operations with quasivisual grain occur the global structure will be construed as looming in the background.

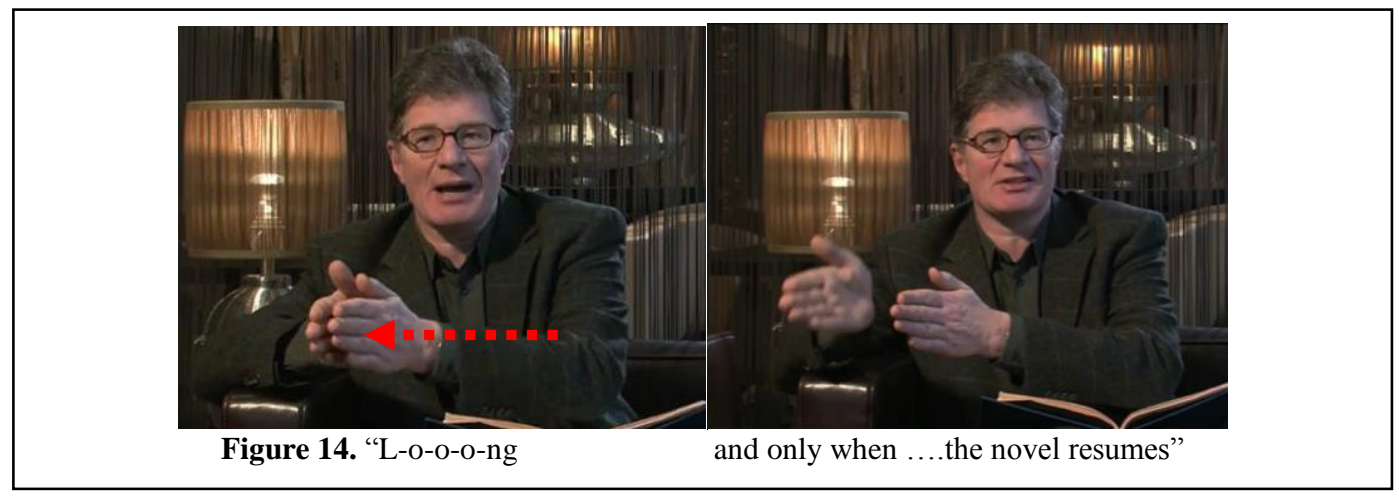


PJOS 5(2), 2013

In presenting Angel Vasquez' La vida perra de Juanita Narboni Willemsen describes the author's merit as follows (2:38).

(15) die Ent ${ }^{`}$ wicklung [einer Ep^oche], the development of an epoch

['aus dem 'Geist des 'inneren Mono]^loges heraus.

from the spirit of the inner monologue out-of

Willemsen uses both hands to characterize this development or emergence as an arc. The gesture and the matching verbal metaphor out of, which the arc semantically maps onto, clearly instantiate CAUSATION IS EMERGENCE (cf. Turner, 1996). We may understand this as a variant of FORCE-PATH-based causation in which the starting point is the cause and the end point the effect. The topic is the creation of a literary effect through a stylistic device. Inner monologue causes a particular perception in the reader. Note, finally, that the four or five beats on the path, while accentuating almost every word, might be additionally interpreted as emphasizing the development over multiple stages.

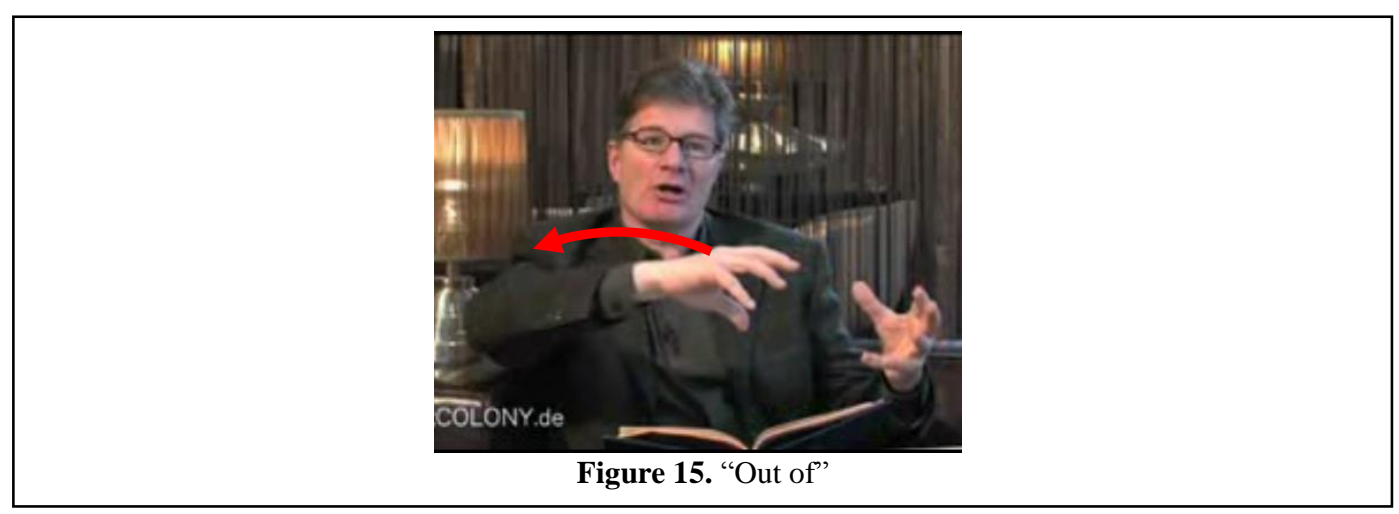

Let us move to an extended, final example. In discussing Richard Yates's Revolutionary Road, Willemsen starts as follows (0:16).

(16) [^unbedingt 'wissen zu 'wollen], at all costs know to want

wie die [^Spannungs'linie 'die=ses 'Buches], / ver^laufen wird.

how the tension line of this book run will

The conveyed idea is that after twenty pages the readers will want to know how excitement and suspense will develop in the novel. The accompanying bi-manual forward arc gesture has distinct phases. It slopes up, reaches a round peak, then plummets briefly, only to subside gradually with an undulation through a suddenly lessening of the angle, at which point the motion is noticeably accelerated and stylized. (In Figure 16 the sloping can be detected in the slight difference in hand rotation in the middle two frames compared to the first and fourth frames.) This complex dynamic shape creates a pretty distinct 3-D image of an arc with variable spatio-temporal properties. Since the topic expressed verbally is suspense the two channels together suggest the generic mapping 
AFFECT IS A CONTOUR, concretized as INTENSITY OF SUSPENSE IS UP (see below). The sloping arc, in its up-down dimension and in its specific manner of motion, represents a reduced gestural rendition of a vitality affect contour such as is commonly experienced as somatic pangs, flushes, crescendos, flutters, etc. Here, the holistic contour properties stand for how the story as a whole unfolds affectively (for the reader). I would think that what Willemsen presents here is a generic contour expressing only the idea of affect over time as such without specifics beyond change and iteration.

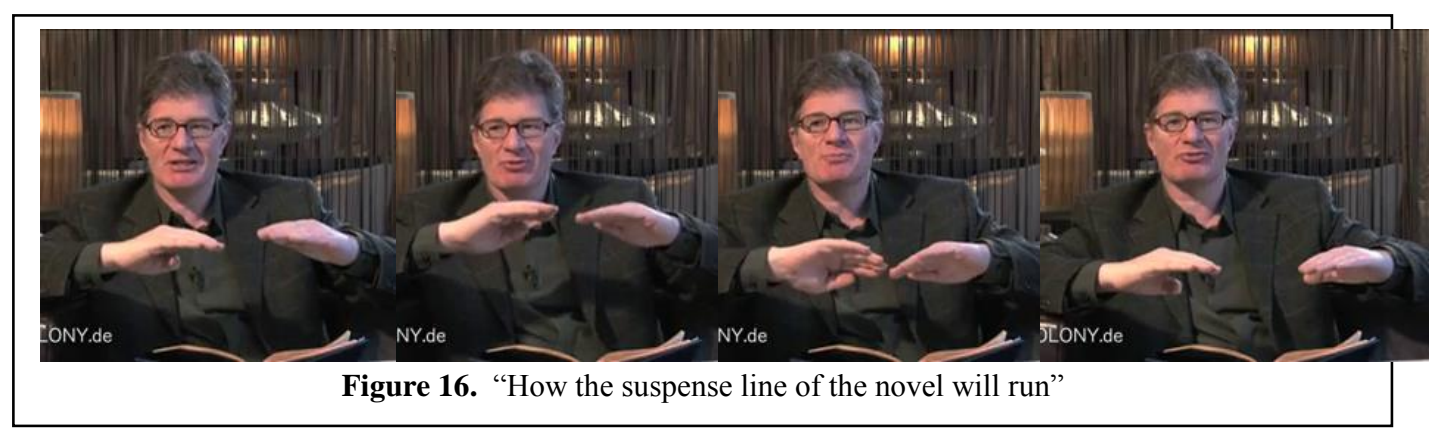

Willemsen then continues his sentence $(0: 21)$.

(17) das heisst auch / zu ver[^folgen], that means also to follow

[wie der 'seismische ${ }^{\wedge}$ Stoß], / der ['ganz am ${ }^{\wedge}$ Anfang dieses Ro'manes] 'steht how the seismic impetus that wholly in the beginning of this novel stands

The idea is that readers will follow an initiating event with the force of a seismic impetus. The verbal metaphor expressing REMARKABLE CONTENT IS A POWERFUL FORCE is replicated gesturally through the repetitive forward shaking of both hands, which through kinetic intensity mimics an earthquake. The subsequent phase of the gesture (no figure) creates an arc-like trajectory from left to the far right. The synchronous words in the course of the novel make plain that it stands for a timeline and the process that is continuous, but without emphasis.

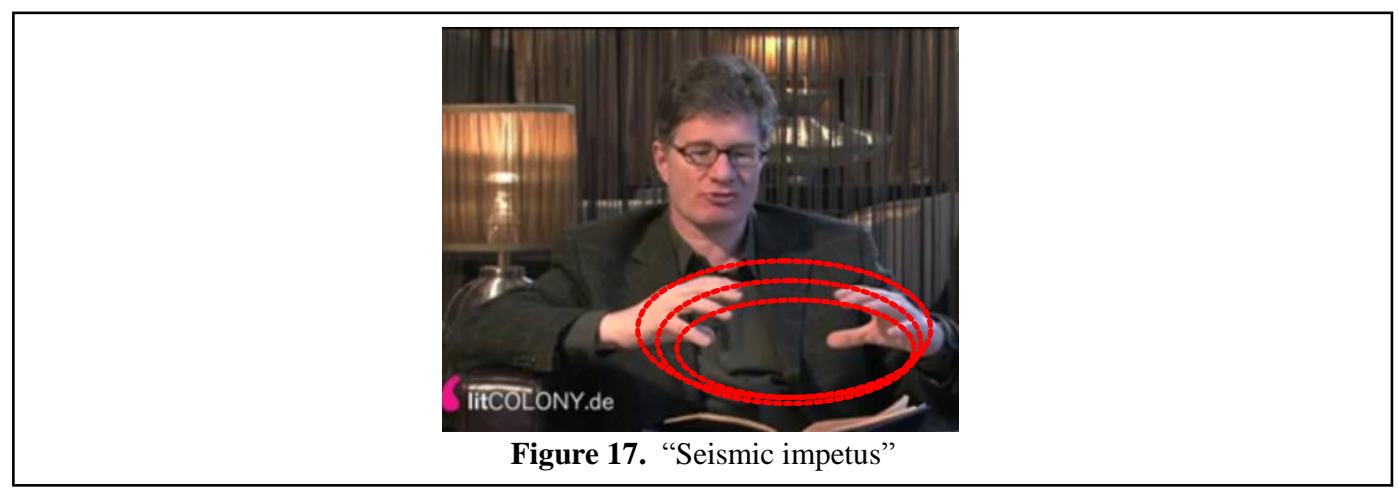


PJOS 5(2), 2013

The sentence then continues with a still new kind of gesture.

(18) $\left[\operatorname{sich~im~}^{\wedge}\right.$ Laufe] des Ro'mans, / [^auf], / ['oder^abbaun] wird itself in the course of the novel up or down-build will

Both of Willemsen's hands are raised to a higher and then dropped again to a lower level, while he conjectures that the readers want to know if the impetus will build up or diminish. The vertical moves are precisely synchronized with the words up and or down. Verticality here maps on the reader's expectation of what is to come, viewed in terms of the metaphorical mapping INTENSITY OF SUSPENSE IS UP. It invites comparing the initial story event to possible others lying ahead. Another possible implication Willemsen might have in mind is that the seismic impetus is the initiating event of a causal chain and that the sentence refers to the causal propagation of impetus to subsequent events, yet another instance of the "billiard-ball" model (CAUSAL CONTINUITY IS CONSERVED IMPETUS). The same idea may implicitly underlie the dispersal gesture in Example 4.

Let me point out some cross-connections here. Since the speaker takes a reflexive stance towards the author-recipient relationship, effects on the audience may be said to belong to more or less the same generic target domain as the author's skill or his employed literary devices (e.g. CREATIVITY IS PHYSICAL EFFORT, Example 9). In line with this, the speaker may also reflect upon his own management of the material, as was the case in a gesture that seemingly wipes the previous gesture away while saying that is not important (Example 7). This suggests an act of dynamically arranging "story objects" to recreate what is most important for the summary. Implicitly perhaps, the retelling is thought of as conjuring up and then configuring entities in space (STORYTELLING IS ARRANGING OBJECTS).

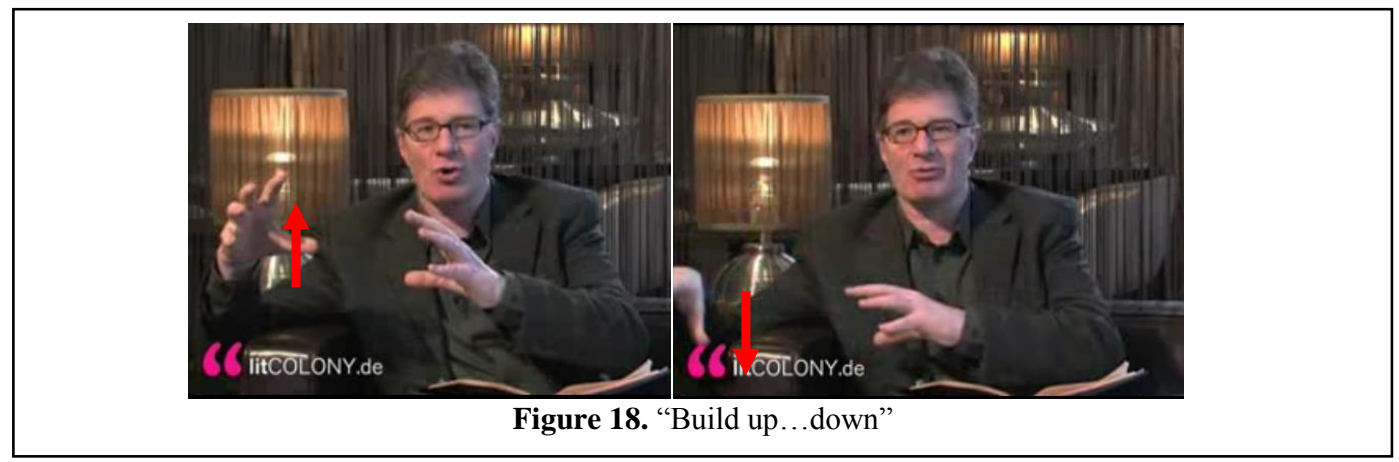

\subsection{Further short examples}

Miscellaneous further speech-gesture pairings may be summarized:

(19) "an author searches access to the foreign" (narrowing path gesture) (Bouvier 0:18; lines 258-263)

$\rightarrow$ THEMES/EMOTIONAL STATES ARE CONTAINERS and, by implication, WRITING IS A PATH

(20) "[the work] sometimes lets flash up a smart thought" (quick one-hand upwards sweep) (Schütt 1:45; lines 279-281)

$\rightarrow$ INTENSITY OF EFFECT ON READER IS UP / QUALITY OF PLOT IS UP 
(21) "such processes of destruction in psychological relations, including marriages [...] are themes for Richard Yates" (ball-shaped hands with iterative screw-like countermotion) (Yates 3:10; lines 283-300)

$\rightarrow$ SIMILAR STORY EVENTS ARE ITERATIVE MOVEMENTS

(22) "state of disarray" (both hands make a plane) (Klein 1:23; lines 302-314)

$\rightarrow$ STATES ARE PLANES

(23) "very pro-American news-coverage" (pinching fingers pick out this theme-item) (Klein 2:25; lines 321-325)

$\rightarrow$ STORY THEMES ARE AN OBJECTS / TREATING A THEME IS OBJECT MANIPULATION

(24) "[the character] is not developed from within, he is only described, but not expressed" ( 3 gestures: pulling out from the heart with a palm upwards flap, plane formed by the hands, then a repetition of first gesture) (Tolstoi 2:38; lines 327-346)

$\rightarrow$ EXPRESSION IS EXTERNALIZATION (in the center-periphery and in-out dimension) and possibly CHARACTER DEVELOPMENT IS A PATH (in the front-back dimension)

\subsection{Overview of gesture types and functions}

The list could, no doubt, be continued by examining a larger corpus, or by exploring subelements (cf. the detailed work on paths by Forceville and Jeulink 2011: 41). To recap, the gestures from my small corpus are used for a variety of purposes. Typologically, it seems that a basic distinction runs between (a) gestures that bestow an entity- or container-like ontology on stories as a whole, their scenes, or their main motifs and themes and (b) gestures that convey the inner temporal, causal, intentional, and possibly also hierarchical macro-structure of a story. The former category includes gestures that emphasize abstract qualities, including difference, number, and importance. The latter category focuses on process related construals. We may note in this context that some processual gestures reflect on the activity of storytelling itself, be it the author's activity ("develop [the character] from within") or the reader's ("dig through the novel like through a quarry"). Quite many other gestures relate to emotional or suspense effects on the reader. Arguably, all this metanarrative discourse, which focuses on motivations to write and on the effects of reading, takes a more distant stance towards the story, i.e. a broader viewing arrangement that includes literary producers and recipients on top of the texts as such.

To rephrase it functionally, storytellers use gestures to summarily highlight topics, to perspectivize or give other "stage directions", to express processual relations, to evaluate an episode or experience, and to reflect on the effects of storytelling. Several or even most of the reviewed mappings appear to be domain-specific derivatives of generic metaphoric gestures that one finds outside narration as well, e.g. IMPORTANT IS UP, TIME IS A PATH, or CAUSATION IS EMERGENCE. This is unsurprising because many everyday domains are steeped in narrativity to begin with, given how basic it is to humans.

The summarizing Table 1 connects functional roles with the image schema types that go with them. For purposes of overview I include further mappings that either logically complement the gestures discussed here in Section 3 or that seem likely in view of theoretical work on narrative (see Section 2). These are marked by parentheses in the right column. 
PJOS 5(2), 2013

Table 1. Types of spatial mappings to narrative structure

\begin{tabular}{|c|c|c|}
\hline $\begin{array}{l}\text { Metanarrative } \\
\text { function }\end{array}$ & Subtypes & $\begin{array}{l}\text { Image-schematic shape of } \\
\text { gesture }\end{array}$ \\
\hline $\begin{array}{l}\text { Perspective of } \\
\text { summarization }\end{array}$ & Perspective on attributes vs. process & $\rightarrow$ (Switch from Paths to Objects) \\
\hline Scenes & $\begin{array}{l}\text { Story parts, scenes } \\
\text { "Zoom in": Change from summary to } \\
\text { detailed focus on scene } \\
\text { "Zoom out": Change from detailed to } \\
\text { summary focus } \\
\text { Maintenance of scene focus }\end{array}$ & $\begin{array}{l}\rightarrow \text { Container/Space } \\
\rightarrow \text { Container suddenly created } \\
\rightarrow \quad \text { (Discontinued Container) } \\
\rightarrow \quad \begin{array}{l}\text { Emphatic lingering on } \\
\quad \text { Container, Beats }\end{array}\end{array}$ \\
\hline $\begin{array}{l}\text { Temporal } \\
\text { dynamics }\end{array}$ & $\begin{array}{l}\text { Temporal progression (global) } \\
\text { Temporal continuity } \\
\text { Tempo of action }\end{array}$ & $\begin{array}{l}\rightarrow \text { Intervals on Path } \\
\rightarrow \text { Connected Path segments } \\
\rightarrow \text { Gradual vs. quick shift }\end{array}$ \\
\hline $\begin{array}{l}\text { Temporal } \\
\text { breakpoints }\end{array}$ & $\begin{array}{l}\text { New scene begins } \\
\text { Next scene continues } \\
\text { Scene ends } \\
\text { Number of scenes or sub-scenes }\end{array}$ & $\begin{aligned} & \rightarrow \text { Path segment begins, Arc-up } \\
& \text { Path segment ends, another } \\
& \rightarrow \text { Path segment begins } \\
& \rightarrow \quad \text { (End-delineation of Path), Arc- } \text { down } \\
& \rightarrow \quad \text { Segments on Path }\end{aligned}$ \\
\hline $\begin{array}{l}\text { Flashbacks and } \\
\text { flashforwards }\end{array}$ & $\begin{array}{l}\text { Speaker's discourse rearranges parts } \\
\text { of the (implied, cognitive) story }\end{array}$ & $\begin{aligned} \rightarrow & \text { (Pointing on a Path, } \\
& \text { Changes between Planes) }\end{aligned}$ \\
\hline Themes or motifs & $\begin{array}{l}\text { Main themes or motifs ("essence") } \\
\text { Number of main themes or motifs } \\
\text { Theme development } \\
\text { Theme not followed through with } \\
\text { Importance of scene or theme } \\
\text { Difference/incompatibility of themes } \\
\text { Topic evaluation or change: "but that } \\
\text { is not so important" }\end{array}$ & $\begin{aligned} & \rightarrow \text { Planes, Objects apart } \\
\rightarrow & \text { Number of objects or beats } \\
\rightarrow & \text { (Path) } \\
\rightarrow & \text { Path dispersal } \\
\rightarrow & \text { Kinetic intensity, Up } \\
\rightarrow & \text { (Objects, Spaces apart) } \\
\rightarrow & \text { Space change, Force (wiping } \\
& \text { away; setting aside) }\end{aligned}$ \\
\hline Effect on reader & $\begin{array}{l}\text { Intensity of emotion } \\
\text { Dynamics of emotion }\end{array}$ & $\begin{aligned} & \rightarrow \text { Kinetic intensity, Up } \\
& \rightarrow \quad \text { Shaking /Trembling, Motion } \\
& \\
& \text { contours (slopes, etc.) }\end{aligned}$ \\
\hline $\begin{array}{l}\text { Experiential states } \\
\text { of protagonists }\end{array}$ & $\begin{array}{l}\text { Protagonist's emotional/ belief states } \\
\text { State differences } \\
\text { State changes }\end{array}$ & $\begin{array}{l}\rightarrow \text { Planes, Spaces } \\
\rightarrow \quad \text { Spaces apart } \\
\rightarrow \quad \text { Spaces on Path }\end{array}$ \\
\hline Causality & $\begin{array}{l}\text { Causal event } \\
\text { Cause-Effect } \\
\text { Compellingness of cause } \\
\text { Causal coherence / continuity } \\
\text { Causal incoherence (e.g. insert) } \\
\text { Uncertain causality }\end{array}$ & $\begin{aligned} & \rightarrow \text { Arc-Path, Emergence } \\
\rightarrow & \text { Start- vs. End-point; } \\
& \text { Bottom vs. Top } \\
\rightarrow & \text { Kinetic intensity } \\
\rightarrow & \text { Unbroken Path chain, Force } \\
& \text { impetus conserved } \\
\rightarrow & \text { Broken Path chain } \\
\rightarrow & \text { (Tentative manner of motion) }\end{aligned}$ \\
\hline $\begin{array}{l}\text { Goal hierarchy, } \\
\text { embedded plots }\end{array}$ & Subordinate vs. main goals & (Nested Spaces, Verticality) \\
\hline Author's activity & $\begin{array}{l}\text { Writing, character development } \\
\text { "Externalizing" an idea } \\
\text { Style } \\
\text { Creativity, intense storytelling }\end{array}$ & $\begin{array}{l}\rightarrow \text { Path } \\
\rightarrow \text { Path out of Container } \\
\rightarrow \text { Texture of object } \\
\rightarrow \text { Kinetic intensity }\end{array}$ \\
\hline
\end{tabular}


M. Kimmel

\subsection{The relationship between gesture and speech}

An important observation concerns the respective roles of gesture (G) and speech (S) with regard to narration, as depicted in this summary of the examples 1-19.

Table 2. Speech and gesture in relation to one another

\begin{tabular}{|c|c|}
\hline $\begin{array}{l}\mathrm{G}+\mathrm{S} \text { fully } \\
\text { metanarrative }\end{array}$ & $\begin{array}{l}\text { "encounter with death, with chaos" } \\
\text { "run blindly into the void" } \\
\text { "real scenes or dreamt scenes" } \\
\text { "but that is not so important" }\left(2^{\text {nd }} \text { part of Example } 7\right) \\
\text { "extracts [of Peymann's life] which are to different degrees } \\
\text { loadable, ... which are sometimes purely amusing" } \\
\text { "which are often surprising" (last part of Example } 8) \\
\text { "now has inspirational thrusts"/ "time and again he has an } \\
\text { idea" } \\
\text { "a lyric fragment" } \\
\text { "there follows an insert in which all threads of the novel are } \\
\text { cut" } \\
\text { "and we suddenly - completely in isolation - experience ..." } \\
\text { "the development of an epoch out of the spirit of inner } \\
\text { monologue" } \\
\text { "how the suspense line of the novel will run" } \\
\text { "readers want to know if the impetus will build up or decrease" }\end{array}$ \\
\hline $\begin{array}{l}\text { G metanarrative/ S both } \\
\text { metanarrative and } \\
\text { narrative }\end{array}$ & $\begin{array}{l}\text { "he leads the war because the Emperor has - as it were - } \\
\text { disappointed him" } \\
\text { "once, even a woman appears" ( } 1 \text { st part of Example } 7) \\
\text { "every now and then an immediate perception passes over into } \\
\text { an existential mood" } \\
\text { "a son at his mother's deathbed in a lo-o-o-ng process of } \\
\text { agony" }\end{array}$ \\
\hline $\begin{array}{l}\text { G metanarrative/ S } \\
\text { purely narrative }\end{array}$ & "He meets his first love" \\
\hline $\begin{array}{l}\text { G narrative }+S \\
\text { metanarrative }\end{array}$ & - \\
\hline
\end{tabular}

Most frequently gesture and speech are both metanarrative, such as when saying "motifs run blindly into the void" with a corresponding gesture $(\mathrm{N}=13)$. In other cases a metanarrative expression (appearing in italics) serves as an anchor for an equally metanarrative gesture, while further semantic content adds specifics of the storyworld, such as in "because the Emperor has disappointed him" $(\mathrm{N}=4)$. Only once, in the phrase "He meets his first love", the metanarrative gesture is accompanied by speech with an exclusively narrative meaning $(\mathrm{N}=1)$. This avoids a redundancy of semiotic channels (cf. Mittelberg, 2010: 376f.), if we set aside the fact that prosody signals the status of key scene here. Of course this quick analysis only considers words uttered during the gesture. Considering more co-text will ostensibly lead to still more cases with a degree of speechgesture redundancy. All this makes perfect sense. Speech tends to include synchronized metanarrative cues simply because inferring a gesture's metanarrative status from the context alone is difficult. Secondly, what is striking is that the combination of purely metanarrative speech - if such exists - with narrative gesture remains virtually absent. Obviously, we need to replicate this with more speakers and in different discourse 
PJOS 5(2), 2013

contexts. While we will surely get a higher overall frequency of content-related gestures in non-summarizing discourse, my guess is that these will seldom combine in precise sync with structural speech cues.

\subsection{Gesture dynamics}

The kinetic continuity between different gestures is conspicuous. For example, in Examples 12 and 13 we see how an imagistic feature of the scissors gesture, a closing boundary, lingers on in the rigid palms that now delineate a space for the purported thematic insert. In many places we also see considerable kinetic economy when one target domain morphs into another by slightly changing hand positions, e.g. where a balllike object stands for a literary style and fluidly straightens out into a forward darting bounded conduit standing for the idea of immediacy (Examples 10 and 11). This reflects what Herman (2010) calls transpositions of gesture spaces. Generally speaking, shifts from one metanarrative function to the next can be more or less radical. Langacker's notion of scene construal (1987) and Herman's (2009: 104f) argument for its narratological application are suggestive, as they may help us distinguish two types of dynamics: Shifting from the global time structure to a zoom-in on a scene retains the dynamic construal and merely changes the granularity. A more radical shift would change the construal type itself. Suppose that a scene with internal processuality comes to be summarily conceived as the carrier of a particular quality in the subsequent gesture, e.g. when moving from timeline to a thematic container space conjured up through a pinching gesture. Here, the kind of metanarrative representation changes more radically. While the timeline foregrounds the continuous, temporally extended nature of the narrative, the thematic space draws attributes together transversally for a static construal.

\subsection{Gesture laminations}

Gesture lends itself to multifunctionality (Kendon, 2004; Calbris, 2011) and to laminations (Herman, 2010). For example, once a story theme has been rendered entitylike in our mind, this image easily synthesizes with object- and attribute-related metaphors such as DIFFERENT IS APART. Recall from Example 3 how Karasek identifies two main motifs via object presenting gestures, where the emphatic intensity stands for importance, while the number of strokes stands for the number of motifs. Sometimes, the elements of a lamination become fully synthesized while in other cases, more distinct image-schematic features convey potentially independent meanings. In fact, sometimes one image-schematic aspect like "container" persists while another like "sharply bounded" fades away. Another way in which a single gesture can become multifunctional concerns the multiple topics an image-schematic source domain comes to express. Certain laminations assign two or more metaphorical targets to the source. This occurs in Example 20 where verticality can be read in two (metonymically linked) ways, as GOOD PLOT IS UP, as INTENSE PLOT IS UP, or both. Something similar happens in Example 13 where the scene and its theme are amalgamated in the container image.

As an afterthought, image schemas gestured earlier may serve to construct a ground frame which the speaker later refers back to (Mittelberg, 2010). The presently actualized gesture then becomes the figure against the ground that remains vivid in shortterm memory. Hereby, speakers may build complex narrative scaffolds in a single 
conceptual substrate as I have stressed elsewhere (Kimmel, 2005b, 2008b). ${ }^{11}$ Thus, image schemas may add up and be synthesized within a multi-track model of the story in which CONTAINERS, NEAR-FAR, PATHS, UP-DOWN and FORCES complement each other. One gestural hint of this was seen in Karasek's emphatic hold at an important juncture, which may invite the audience to mentally add the mapping that STORY EVENTS ARE POINTS ON A PATH so as to construe the hold as a halt on the narrational journey to be zoomed in on.

\section{Discussion: Why spatialized form helps narrate}

The use of metanarrative metaphoric gestures indicates a need on the part of the speakers to conceptualize structural aspects of a story either for their own benefit, that of the listener, or both. This section will inquire into the expressive and cognitive gains afforded. I will also strive to disentangle theoretical claims that appear similar, but are in fact not fully co-extensive.

\subsection{Conceptual metaphors and ICMs for narrative structure}

The sampled gestures are readily understood by native speakers and none of them appear particularly idiosyncratic, over-sophisticated, or rare. If the reader agrees with this verdict of mine, the possibilities are that (a) the gestures are fully conventional, (b) they build on rough templates that contextually generate meaning, or (c) they are assembled ad hoc by speaker and audience. Which of these readings is correct? We must proceed with care in view of a lively debate about the fixity of metaphor generating templates (McGlone, 1996; Keysar et al., 2000; Gibbs, 2005), hence the reality of conceptual metaphors. Strictly speaking we need to remain agnostic until larger studies are completed, yet even my small corpus tentatively points to some image-schematic mappings being recurrent, as summarized in Table 1. I am rather confident that positing a set of adaptable and variously combinable conceptual metaphors of narrative structure (cf. Lakoff and Johnson, 1999) is not overblown in light of all the additional evidence reviewed in Section 2. However, we must not exclude the possibility that some such conceptual mappings are negotiated between the speaker and the audience on the spot or softassembled from lower-level constituents, rather than being fully conventional.

The theoretical status of my claim also deserves inquiry from a slightly different angle. Ultimately, my data constitutes evidence for what Lakoff (1987: 283), dubs "spatialization of form". His wide-ranging proposal emerges within his theory of Idealized Cognitive Models (ICMs) (see also pp. 68, 154) and reads as follows:

\footnotetext{
What I will be claiming is that the same schemas structure concepts themselves. In fact, I maintain that image schemas define most of what we commonly mean by the term 'structure' when we talk about abstract domains. When we understand something as having an abstract structure, we understand that structure in terms of image schemas. [...] spatial structure is mapped into conceptual structure. More specifically, image schemas (which structure space) are mapped into corresponding abstract configurations (which structure concepts). (Lakoff, 1987: 283)
}

\footnotetext{
${ }^{11}$ These text-linguistic case studies of metaphors in Joseph Conrad's Heart of Darkness argue for image schema cues being deployed over the text so as to become complementary. The underlying assumption is that the reader actively makes an effort to create a coherent story model in a "mental sketchpad" that integrates knowledge of different kinds (cf. Baddeley, 1986). For example, agents move between container-like existential spaces impelled by causal forces and held back by others. This summary image of plot creates a natural mutual fit of image schemas from different story tracks (see 2.3).
} 
PJOS 5(2), 2013

Speaking of "spatialization of form" comes down to saying that conceptual formats are image-schematic in the same way that some word meanings, e.g. prepositions, are. Lakoff pitches his hypothesis broadly to include grammatical as well as conceptual forms in scenarios, scripts, folk theories, and cultural models. Although he sees image schemas just as one possible principle for structuring ICMs, Lakoff speculates extensively about three areas of applications (pp. 289ff), the first of which are complex cognitive models.

Table 3. General ICM types listed by Lakoff (1987)

a. Propositional models are wholes with argument and predicate parts that are connected by semantic relations through LINKS.

b. Scenarios or scripts are SOURCE-PATH-GOAL schemas in the time domain, with a PART-WHOLE structure among elements and causal or identity relations represented as LINKS.

c. Feature bundles such as classical Aristotelian categories are CONTAINERS.

d. Classical taxonomies have elements represented by CONTAINER schemas and hierarchy represented by PART-WHOLE and UP-DOWN schemas.

e. Radial (graded) category structure: The overall category is represented as CONTAINER and the subcategories as nested containers (PART-WHOLE again) which stand in a CENTER-PERIPHERY relation and are connected by LINKS.

f. Graded category membership has no sharp CONTAINER boundaries, but boundary zone in which a SCALE is operative. Graded propositions may define the degree to which a property holds in a similar way.

A second area concerns connective mappings between and within domains.

g. Metaphoric mappings: The notions of source and target are represented as CONTAINERS and the mapping itself as SOURCE-PATH-GOAL schema [implicitly domains must be non-coinciding].

h. Metonymic mappings involve a single domain, possibly structured as container or nested containers (PART-WHOLE), and a stands-for relation, a SOURCE-PATH-GOAL schema.

A third area to which Lakoff applies image-schematic ICMs concerns linguistic relations.

i. Lexical items are defined as elements of an ICM (PART-WHOLE) and against its background (possibly FORWARD-BACKWARD or FIGURE/GROUND)

j. Grammatical categories rely on radial categories (see above).

k. Grammatical constructions and syntax: hierarchical structures are PART-WHOLE schemas, with the mother node being the whole, head-and-modifiers structures are CENTER-PERIPHERY schemas; grammatical relations and co-reference relations are LINKS; syntactic distance is represented by LINEAR SCALES; and syntactic categories are CONTAINERS (presumably graded or not).

Narrative is of such obvious importance for studying spatialized form that its absence from the list seems surprising (although scripts and scenarios are mentioned in passing). Be that as it may, Lakoff's cursory characterization of ICMs illustrate the impressive scope of his claim concerning human cognition. Evidently, his proposal is not a modest one: It amounts to no less than saying human cognition is embodied all the way up to structural forms and cognitive tools. The way I interpret Lakoff, spatialized ICMs comprise generic "formatting instructions" or "templates" used for sequencing, 
partitioning, arraying, or otherwise structuring conceptual items. The generic nature of ICMs allows them to combine with diverging kinds of content. The same ICM gets deployed rather independently of what gets categorized, which kind of sentence is structured, which features are bundled, and so forth. In other words, any structural format can accommodate different kinds of content.

Unfortunately, in the years following Lakoff's book spatialized form was scarcely studied. Only Deane (1992, 1996) addresses it explicitly, although Turner's (1991) and Oakley's (2005) analysis of argumentation-as-force may be seen as implying ICMs of a certain type. Only the recent surge of gesture studies seems to have rekindled interest in ICMs, even if the notion itself has fallen into disuse and even if the method's full potential for addressing ICMs in various cognitive domains has not yet been exploited. Sweetser (2007) speaks about abstract mental spaces in relation to gestural data. A more extensive empirical study by Mittelberg $(2003,2010)$ investigates teachers of linguistic theory. She found that conceptualizations of content, morphemes and words, categories, sentences, and many special concepts that play a role in academic theories of grammatical structure (e.g. nodes, branches, semantic roles, subordination) rely on image schemas, which are expressed with the fingers, hands, and arms. Mittelberg's earlier work on pictorial metaphor (2002) backs this claim up. Finally, although work on abstract thought by Gärdenfors (2000) and Casasanto (2005) points in the right direction, psycholinguists have apparently not approached the narrower topic of ICMs prior to recent work of my own. The experiment in question attempts to adjudicate the issue by using gestures to prime particular reading patterns (Kimmel ms., cf. Kimmel 2008b). My findings are encouraging, as a story's causal-intentional arc activates different variants of FORCE, depending on whether main goals are reached at once, temporarily impeded, or fully thwarted. $^{12}$

\subsection{Dynamic meshing between content and structure}

What of the structure-content dialectic that was briefly mentioned earlier? It seems that metanarrative image schemas support the expression of story content by providing it with what I have called "co-signatures" (Kimmel, 2002). This is just another name for ICM scaffolds, with an emphasis on the fact that the latter co-evolve around content (such as what happens in a story scene) and bestow form on it. Hence, in storytelling form and content mesh dynamically in ways that make it difficult to determine whether bottom-up or top-down driven mechanisms dominate. By further implication multiple timescales must be dynamically connected: Global mechanisms from genre templates or the storyteller's foreknowledge of events to come provide structural co-signatures to locally unfolding scene content. Hence, image-schematic story ICMs must unfold on a parallel track to organize this content.

Metanarrative data that co-occurs with content-related data, whether in words or gestures, is strongly suggestive of such a dialectic. For instance, by creating two gestural tiers a speaker structures the simultaneous verbal mention of two topics that get "filled

\footnotetext{
${ }^{12}$ The subjects had to prepare for a bi-manual force gesture while reading a simple text about a protagonist with some goal. Both cognitive tasks had to be carried out concurrently. Force gestures matching the story (e.g. unbroken causal flow - unbroken force) led to increased reading speed of target sentences as compared to gesture-plot mismatches. It was also found that visual depictions of image schemas in gesture videos are insufficient to create a priming effect. Instead, motor preparation for the gestures is required. Note, finally, that the texts were purged of local force semantics and especially of metaphorical force expressions in order to ensure that the effect must owe to the global story structure inferred by the readers.
} 
PJOS 5(2), 2013

into" the gestural template. In this way the hands provide formatting instructions for the content. The co-evolving format and content layers reveal something crucial about the formation dynamics of sequential thought in general and, in particular, about how storytelling requires structural relations between content elements to make sense. Cospeech gestures open a window on this otherwise opaque dialectic. In other words, the work-sharing arrangement between the two semiotic channels showcases the cospecificity of and synchronization patterns between these cognitive layers.

\subsection{Why structural gesturing?}

To tackle the issue from a slightly different angle, why do speakers externalize story ICMs through gesture rather than just thinking them? The almost incessant gestural flow suggests that foregrounding the format of a story qua format pays off for our two storytellers. Metanarrative gestures seem to be indispensable tools for them, especially for Willemsen who has a quite limited timeframe to communicate his key ideas. Given this, what may such gestures' cognitive-mnemonic or pragmatic-communicative benefits be (Cienki, 2008: 17)? First, metanarrative gestures provide stage directions for the audience by highlighting specific story elements, dynamics, or viewpoints. They help navigate through complex construal shifts and occur at critical narrative junctures. And they are most present in dynamic and unpredictable spots, or, conversely, as McNeill (2005: 103) has it, "[t]he greater the continuity with the immediate past, the less the elaboration of the present". Condensed retellings therefore encourage persistent gesturing in general and metanarrative gestures in particular whenever quick shifts in theme or perspective need to be effectively staged. I would like to stress, nonetheless, that gesturing is not exclusively due to the cognitive demands of highly compressed discourse. When I conducted two interviews of 75 minutes each, asking the informants to discuss and compare stories at some length, metanarrative gestures were rather abundant.

Secondly, gesticulation may provide the speakers themselves with thinking scaffolds that lessen cognitive effort (Goldin-Meadow et al., 2001). Gestures can prime temporarily inaccessible lexical items, facilitate word-meaning linkages, and organize information for the act of speaking. Also, processing demands can be off-loaded to visual logic by virtue of perceptual anchoring in the gesture space (cf. Spivey et al., 2005 on quasi-visual memory pads). Gestures are "fixing aids". To illustrate the idea, take a speaker who first demarcates two story topics as theme-containers with one hand each, then zooms in on one of the two verbally, while keeping the other in place as a reminder, which she eventually returns to by re-animating the frozen hand. Providing a crisp, yet interpretively rich summary that interconnects many aspects of a story is a complex task which gestures lend cognitive economy to.

While metanarrative gestures impose a basic format on story comprehension, they may equally support re-interpretations after the fact. In re-telling or summarizing a novel, formatting operations, such as zooming into a scene, reflect how the speaker chooses to select specific aspects from episodic memory. Often, this allows configuring the elements in a new way, e.g. when similarities between episodes or the developments in an Entwicklungsroman are evaluated. This secondary re-interpretation process is, above all, reflected in gestures that pick out summary themes or motifs. Throughout, many alternative construals can be chosen by the speaker who guides this selectivereconstructive process and fashions it to fit the audience (e.g. telling it to children), the conversational context (e.g. summarizing vs. impressionistic recounting), and the desired emphasis. 
Do storytellers who gesture less frequently constitute counterevidence to these cognitive claims? I doubt it, because all narratively competent adults understand metanarrative gestures passively. Speakers whose thought exclusively employs nonspatial ICMs will become unable to comprehend other gesturers effortlessly and will miss out on crucial aspects of the story. To sum this up, on a weak hypothesis ICM gestures situatively off-load cognition to the hands when things get difficult. On a stronger hypothesis which is subject to future testing, but also my provisional guess, ICMs are obligatorily activated in the mind whether or not their imagery is externalized in gesture (or, indirectly cued through verbal metaphor). If this view turns out to be the correct one, the only reason why we don't always see ICMs externalized is that some individuals with greater attentional resources do not need explicit cues as much as others.

\section{Conclusion}

The discussion of metanarrativity speaks to issues surrounding structural cognition, notably its representational format, its underlying generative mechanisms, and its process dynamics:

- Metaphorical story gist descriptions and metaphorical co-speech gestures both testify to the abundant use of spatialized form for metanarrative purposes, although they leave open the extent to which spatialization is obligatory.

- As to generative mechanisms we cannot rule out ad hoc assembly, but the evidence leans toward the emergence of metanarrative metaphors from a set of conceptual metaphors for storytelling, given that spatialized forms are (a) readily understood by native speakers, (b) many of them recur even in my small corpus, and (c) converge with independent evidence on general conceptual metaphors for causality, time, ontology, etc.

- As to the dynamic interweaving of the narrative and the metanarrative layers, spatialized forms create structural ICMs/co-signatures which co-evolve with content. In the work-sharing agreement between gestural and verbal "channels", gesture seems to specialize somewhat on the metanarrative channels in the present data.

Gestural story formatting devices serve three types of representational function. First, they bestow macro-structure on a story by dynamizing, sequentializing, sub-partitioning, causally connecting, and possibly hierarchizing episodic content (FORCE, PATH, CONTAINER/SPACES/PLANES, PART-WHOLE, NESTING). Second, gestures ontologize narrative themes or motifs as objects (CONTAINERS/SPACES, OBJECTS) and relationally organize them by relative positioning or emphasis (APART, KINETIC INTENSITY). Third, the dynamics of co-speech gesture reflect a storyteller's narrative stage management. $\mathrm{He}$ or she decides whether to focus on individual scenes (= local perspective) or a stretch of several episodes (= relative perspective), or, for that matter, whether to choose a summary construal altogether that foregrounds motifs, themes, and attributes $(=$ global perspective).

Future studies should produce a larger inventory of metanarrative gestures, further test the conceptual metaphor hypothesis, inspect the conceptual and kinetic economy whereby narrative and metanarrative gestural elements are combined, and explore the influences of speaker personality and speech context (summary vs. detailed recounting vs. pure commentary with reference to shared knowledge). Yet another aim is to track how 
PJOS 5(2), 2013

speakers traverse between local and global information in storytelling. Finally, given that metanarrative gestures are not easy to come by from all speakers or in all situations, the elicitation of rich enough data poses a challenge. I have run encouraging trials, in which informants were asked to compare story triples on their most similar and most different aspects to generate focused metanarrative discourse ("triad method", Weller and Romney 1988, pp.31-37).

Overall, metanarrative/structural cognition should interest at least three research communities. To cognitive linguists storytelling furnishes a testbed for the arguably strongest embodiment claim in existence, the "spatialization of form" hypothesis. Reaching beyond the ordinary concern of semantics with content, the profound implication is that cognition may be embodied "all the way up". My study, like Mittelberg's, should encourage scholars to scrutinize spatialized ICMs in as many as possible abstract domains and to gather convergent evidence from visual, linguistic, psycholinguistic, and other sources (cf. Lakoff and Johnson, 1999).

To cognitive narratologists spatialized form points to a hitherto unexplored, but appealing way of addressing how time, agency, causality, partonomy, theme units, etc., are conveyed. Assuming that storytellers, as inherent part of their narrative competence, must find some way of crafting ICMs for discourse-related and cognitive purposes, the associated cognitive claim is that any remotely complex conversational narration requires spatio-kinesthetic structuration, as perhaps does storytelling per se! Two reconstructive tasks are incumbent on the narratologist, first as regards the suite of dynamic story construal tools, which allow the speaker to choose between ways of perspectivizing, compression, aspectual emphasis, and so forth; and second as regards the sum total of narrative ICMs, i.e. the non-negotiable fundaments of narrativity that render well-formed stories distinct from recipes, arguments, or dada poetry. To the extent that narrativity must largely reside in a set of structural invariants, the fascinating question is if imageschematic ICMs can fully do the job (cf. Herman, 2002, 2009).

Third and finally, my study suggests new directions for psychological reading research. Those who study imagistic simulation in reading (e.g. Kuzmičová, 2012, 2013, Speer et al., 2009) should widen their scope to include structural formatting devices. To scholars of macro-structures and event indexing (see Section 1) the present evidence on content-form dynamics inspires a fresh look at the relationship between detailed and summary accounts of events. In conclusion, all three contributing disciplines are called upon to pool theoretical and methodological resources, an endeavor - as the present case study demonstrates - they can each gain from.

\section{Acknowledgements}

For their enlightening suggestions I wish to express my gratitude to two anonymous reviewers, to David Herman and Jordan Zlatev, to Eva Müller-Zettelmann, Christine Irran as well as Thomas Eder. Of course, all further inaccuracies remain my own. I also thank Agnes Engleder for her assistance with the transcripts.

\section{References}

Arnheim, R. (1969). Visual thinking. London: Faber.

Baddeley, A. (1986). Working memory. Oxford: Clarendon.

Bartlett, F. C. (1932). Remembering: a study in experimental and social psychology. Cambridge: Cambridge University Press. 
Beardsley, M. C. (1958). Aesthetics. Problems in the Philosophy of Criticism. New York: Harcourt, Brace.

Boltz, M. (1992). Temporal Accent Structure and the Remembering of Filmed Narratives. Journal of Experimental Psychology. Human Perception and Performance, 18(1), 90105.

Bortolussi, M., \& Dixon, P. (2003). Psychonarratology: Foundations for the empirical study of literary response. Cambridge: Cambridge University Press.

Brône, G., \& Vandaele, J. (Eds.). (2009). Cognitive Poetics. Goals, Gains and Gaps. Berlin, New York: Mouton de Gruyter.

Brower, C. (1997). Pathway, Blockage, and Containment in Density 21.5. Theory and Practice, 22, 35-54.

Brower, C. (2000). A Cognitive Theory of Musical Meaning. Journal of Music Theory, 44(2), 323-379.

Buckland, W. (2000). The Cognitive Semiotics of Film. Cambridge: Cambridge UP.

Calbris, G. (2011). Elements of Meaning in Gesture. Amsterdam: Benjamins.

Casasanto, D. (2005). Perceptual Foundations of Abstract Thought. Unpublished Dissertation, MIT.

Cassell, J., \& McNeill, D. (1991). Gesture and the Poetics of Prose. Poetics Today, 12(3), 375-404.

Cienki, A. (2005). Image schemas and gesture. In B. Hampe (Ed.), From Perception to Meaning. Image Schemas in Cognitive Linguistics. (pp. 421-442). Berlin/New York: Mouton de Gruyter.

Cienki, A. (2008). Why study metaphor and gesture? In A. Cienki \& C. Müller (Eds.), Metaphor and Gesture (pp. 5-25). Amsterdam/Philadelphia: John Benjamins.

Cienki, A. (2013). Image schemas and mimetic schemas in cognitive linguistic and gesture studies. Review of Cognitive Linguistics, 11 (2), 417-432.

Cienki, A., \& Müller, C. (Eds.). (2008). Metaphor and Gesture. Amsterdam: Benjamins.

Danaher, D. (2003). A Cognitive Approach to Metaphor in Prose: Truth and Falsehood in Leo Tolstoy's "The Death of Ivan Il'ich". Poetics Today, 24(3), 439-469.

Deane, P. D. (1992). Grammar in mind and brain: explorations in cognitive syntax. Berlin: Mouton de Gruyter 1992.

Deane, P. D. (1996). Neurological Evidence for a Cognitive Theory of Syntax. Agrammatic Aphasia and the Spatialization of Form Hypothesis". In E. H. Casad (Ed.), Cognitive Linguistics in the Redwoods. The Expansion of a New Paradigm in Linguistics (pp. 55-115). Berlin: Mouton de Gruyter.

DuBois, J. W., Schuetze-Coburn, S., Cumming, S., \& Paolino, D. (1993). Outline of discourse transcription. In J. Edwards \& M. D. Lampert (Eds.), Talking data: Transcription and coding in discourse research (pp. 45-89). Hillsdale, NJ: Lawrence Erlbaum.

Fahlenbrach, K. (2010). Audiovisuelle Metaphern. Zur Körper- und Affektästhetik in Film und Fernsehen. Marburg: Schüren.

Ferretti, T., Kutas, M., \& McRae, K. (2007). Verb aspect and the activation of event knowledge. Journal of Experimental Psychology: Learning, Memory, and Cognition, 33, 182-196.

Fludernik, M. (1996). Towards a 'natural' narratology. London; New York: Routledge.

Fludernik, M. (2003). Metanarrative and Metafictional Commentary: From Metadiscursivity to. Metanarration and Metafiction. Poetica, 35(1-2), 1-39. 
PJOS 5(2), 2013

Forceville, C., \& Urios-Aparisi, E. (Eds.). (2009). Multimodal Metaphor. Berlin: Mouton de Gruyter.

Forceville, C., \& Jeulink, M. (2011). The flesh and blood of embodied understanding. Pragmatics \& Cognition, 19(1), 37-59.

Foss, C. L., \& Bower, G. H. (1986). Understanding actions in relation to goals. In N. E. Sharkey (Ed.), Advances in cognitive science (pp. 94-124). Chichester: Ellis Horwood, Ltd.

Gavins, J., \& Steen, G. (2003). Cognitive poetics in practice. London: Routledge.

Gärdenfors, P. (2000). Conceptual spaces: the geometry of thought. Cambridge, Mass.; London: MIT Press.

Goldin-Meadow, Susan, Nusbaum Howard, Kelly, Spencer D., \& Wagner, Susan (2001). Explaining Math. Gesturing Lightens the Load, Psychological Science 12 (6), 516-522

Gibbs, R. W. (2005). Embodiment. Cambridge: Cambridge University Press.

Glenberg, A., \& Robertson, D. (2000). Symbol Grounding and Meaning: A Comparison of High-Dimensional and Embodied Theories of Meaning. Journal of Memory and Language, 43, 379-401.

Graesser, A., Pomeroy, V., \& Craig, S. (2002). Psychological and computational research on theme comprehension. In M. Louwerse \& W. van Peer (Eds.), Thematics (pp. 1934). Amsterdam: John Benjamins.

Greimas, A. J. (1966). Sémantique structurale: recherche et méthode. Paris: Larousse.

Grodal, T. (1997). Moving Pictures. Oxford: Oxford University Press.

Guindon, R., \& Kintsch, W. (1984). Priming Macropropositions: Evidence for the Primacy of Macropropositions in the Memory for Text. Journal of Verbal Learning and Verbal Behavior, 23, 508-518.

Hampe, B. (Ed.). (2005). From Perception to Meaning: Image Schemas in Cognitive Linguistics. Berlin \& New York: Mouton de Gruyter.

Heider, F., \& Simmel, M. (1944). An Experimental Study of Apparent Behaviour. American Journal of Psychology, 57, 243-259.

Herman, D. (2002). Story Logic: Problems and Possibilities of Narrative. Lincoln \& London: University of Nebraska Press.

Herman, D. (2009). Cognitive Approaches to Narrative Structure. In J. Vandaele \& G. Brone (Eds.), Cognitive Poetics. Goals, Gains, and Gaps. (pp. 79-188). Berlin/New York: Mouton de Gruyter.

Herman, D. (2010). Word-Image/Utterance-Gesture. Case Studies in Multimodal Storytelling. In R. Page. New Perspectives on Narrative and Multimodality (pp. 7898). London: Routledge.

Herman, D., Jahn, M., \& Ryan, M.-L. (Eds.). (2005). Routledge Encyclopedia of Narrative Theory. London, New York: Routledge.

Johnson, M. (1987). The body in the mind: the bodily basis of meaning, imagination, and reason. Chicago: University of Chicago Press.

Johnson, M. (1993). Moral imagination: implications of cognitive science for ethics. Chicago; London: University of Chicago Press 1993.

Kendon, A. 2004. Gesture: Visible Action as Utterance. Cambridge: Cambridge UP.

Keysar, B., Shen, Y., Glucksberg, S., \& Horton, W. S. (2000). Conventional language: How metaphorical is it? Journal of Memory and Language, 43, 576-593.

Kimmel, M. (2002). Metaphor, Imagery, and Culture. Doctoral Dissertation, University of Vienna. 
Kimmel, M. (2005a). Culture Regained. Compound and Situated Image Schemas. In B. Hampe (Ed.), From Perception to Meaning. Image Schemas in Cognitive Linguistics, pp. 285-312. New York \& Berlin: Mouton de Gruyter.

Kimmel, M. (2005b). From Metaphor to the "Mental Sketchpad": Literary Macrostructure and Compound Image Schemas in Heart of Darkness. Metaphor \& Symbol, 20(3), 199-238.

Kimmel, M. (2008a). Properties of Cultural Embodiment - Lessons from the Anthropology of the Body. In R. Dirven, R. Frank, T. Ziemke \& J. Zlatev (Eds.), Body, Language and Mind. Vol II. Interrelations between Biology, Linguistics and Culture (pp. 77-108). Berlin \& New York: Mouton de Gruyter.

Kimmel, M. (2008b). Image schemas in narrative macrostructure: combining cognitive linguistic with psycholinguistic approaches. In W. van Peer \& J. Auracher (Eds.), New Beginnings in Literary Studies (pp. 158-184). Newcastle: Cambridge Scholars.

Kimmel, M. (2009). Analyzing Image Schemas in Literature. Cognitive Semiotics 5, 159 188.

Kimmel, M. (2011a): Metaphor Sets in Turn of the Screw - What conceptual metaphors reveal about narrative functions, In M. Fludernik (ed.): Literary Metaphor after the Cognitive Revolution (pp.196-223), Oxford: Oxford University Press.

Kimmel, M. (2011b): From text-linguistics to literary actants - The force dynamics of (emotional) vampirism, Language \& Cognition 3 (2), 235-282.

Kimmel, M. (ms.). Eine psycholinguistische Studie zur Verarbeitung von Plotstrukturen. Vienna: Report to the Vienna City Council MA 7.

Kundera, M. (1988). The art of the novel. London: Faber and Faber.

Kuzmičová, A. (2012). Presence in the reading of literary narrative: A case for motor enactment. Semiotica, 1 (4), 23-48.

Kuzmičová, A. (2013). Mental Imagery in the Experience of Literary Reading. Views from Embodied Cognition, Doctoral Thesis, Stockholm University.

Lakoff, G. (1987). Women, fire, and dangerous things: what categories reveal about the mind. Chicago; London: University of Chicago Press.

Lakoff, G., \& Johnson, M. (1980). Metaphors we live by. Chicago: University of Chicago Press.

Lakoff, G., \& Johnson, M. (1999). Philosophy in the flesh: the embodied mind and its challenge to Western thought. New York: Basic Books.

Langacker, R. W. (1987). Foundations of cognitive grammar. Stanford: Stanford U.P.

Malmo, R. (1975). On Emotion, Needs, and the Archaic Brain. New York: Holt, Rhinehart \& Winston.

Mandler, J. M. (1984). Stories, scripts, and scenes: aspects of schema theory. Hillsdale, N.J: L. Erlbaum Associates 1984.

Mandler, J. M. (1992). How to build a baby: II. Conceptual primitives. Psychological Review, 99, 587-604.

McGlone, M. S. (1996). Conceptual metaphors and figurative language interpretation: Food for thought? Journal of Memory and Language, 35, 544-565.

McNeill, D. (1992). Hand and mind: what gestures reveal about thought. Chicago; London: University of Chicago Press.

McNeill, D. (2005). Gesture \& Thought. Chicago \& London: University of Chicago Press.

Mittelberg, I. (2002). The Visual Memory of Grammar: Iconographical and Metaphorical Insights. metaphorik.de, 02, 69-89. 
PJOS 5(2), 2013

Mittelberg, I. (2003). Making grammar visible: The use of metaphoric gestures to represent grammatical categories and structures. In J. Streeck (Ed.), Proceedings of the First Congress of the International Society for Gesture Studies: 'Gesture - The Living Medium, University of Texas at Austin.

Mittelberg, I. (2010). Geometric and image-schematic patterns in gesture space. In V. Evans \& P. Chilton (Eds.), Language, Cognition, and Space (pp. 351-385). London, Oakville: Equinox.

Müller, C. (2000). Zeit als Raum. Eine kognitiv-semantische Mikroanalyse des sprachlichen und gestischen Ausdrucks von Aktionsarten. In E. W. B. Hess-Lüttich \& H. W. Schmitz (Eds.), Botschaften verstehen. Kommunikationstheorie und Zeichenpraxis. Festschrift für Helmut Richter. (pp. 211-228). Frankfurt a.M.: Peter Lang.

Narayanan, S. (1999). Moving right along: A computational model of metaphorical reasoning about events. Proceedings of the National Conference on Artificial Intelligence (AAAI '99), Orlando Florida, July 18-22, 1999.

Nünning, A. (2001). Metanarration als Lakune der Erzähltheorie: Definition, Typologie und Grundriß einer Funktionsgeschichte metanarrativer Erzähleräußerungen. Arbeiten aus Anglistik und Amerikanistik, 26(2), 125-164.

Oakley, T. (2005). Force-dynamic dimensions of rhetorical effect. In B. Hampe (Ed.), From Perception to Meaning. Image Schemas in Cognitive Linguistics. (pp. 443-473). Berlin/New York: Mouton de Gruyter.

Pecher, D., \& Zwaan, R. A. (2005). Grounding cognition: the role of perception and action in memory, language, and thinking. New York: Cambridge University Press.

Parrill, F. (2000). Hand to Mouth: Linking Spontaneous Gesture and Aspect. Unpublished BA thesis, University of Chicago.

Rumelhart, D. E. (1977). Understanding and summarizing brief stories. In D. Laberge \& S. J. Samuels (Eds.), Basic processes in reading: Perception and comprehension (pp. 265-303). Hillsdale, New Jersey: Lawrence Erlbaum Associates.

Sadoski, M., \& Paivio, A. (2001). Imagery and text: a dual coding theory of reading and writing. Mahwah, NJ: L. Erlbaum Associates.

Speer, N. K., Reynolds, J. R., Swallow, K. M., \& Zacks, J. M. (2009). Reading Stories Activates Neural Representations of Visual and Motor Experiences. Psychological Science, 20, 989-999.

Spivey, M., Richardson, D., \& Gonzalez-Marquez, M. (2005). On the spatial and imageschematic underpinnings of real-time language processing. In R. A. Zwaan \& D. Pecher (Eds.), Grounding Cognition: The Role of Perception and Action in Memory, Language, and Thinking. Cambridge: Cambridge University Press.

Stam, G. \& Ishino, M. (Eds.) (2011). Integrating Gestures. The interdisciplinary nature of gesture. Amsterdam: Benjamins

Streeck, J. (2009). Gesturecraft - The manu-facture of meaning. Amsterdam: Benjamins.

Sweetser, E. (1990). From etymology to pragmatics: metaphorical and cultural aspects of semantic structure. Cambridge: Cambridge University Press.

Sweetser, E. (2007). Looking at space to study mental spaces: Co-Speech gesture as crucial data source in cognitive linguistics. In M. Gonzalez-Marquez, I. Mittelberg, S. Coulson \& M. Spivey (Eds.), Methods in Cognitive Linguistics (pp. 201-224). Amsterdam/Philadelphia: John Benjamins.

Talmy, L. (2000). Toward a cognitive semantics. Cambridge, Mass.; London: MIT Press. 
Trabasso, T., \& Sperry, L. (1985). Causal Relatedness and Importance of Story Events. Journal of Memory and Language, 24, 595-611.

Trabasso, T., \& Suh, S. (1993). Understanding Text: Achieving Explanatory Coherence Through On-line Inferences and Mental Operations in Working Memory. Discourse Processes, 16, 3-34.

Trabasso, T., \& van den Broek, P. (1985). Causal Thinking and the Representation of Narrative Events. Journal of Memory and Language, 24, 612-630.

Turner, M. (1991). Reading minds: the study of English in the age of cognitive science. Princeton, N.J.: Princeton University Press.

Turner, M. (1996). The literary mind. New York: Oxford University Press.

Tsur, R. (2009). Metaphor and figure-ground relationship: comparisons from poetry, music, and the visual arts. In G. Brone \& J. Vandaele (Eds.), Cognitive Poetics. Goals, Gains and Gaps (pp. 237-277). Berlin, New York: Mouton de Gruyter.

van Dijk, T. A., \& Kintsch, W. (1983). Strategies of discourse comprehension. New York; London: Academic Press.

van Peer, W., \& Louwerse, M. (Eds.). (2002). Thematics: Interdisciplinary Studies. Amsterdam: John Benjamins.

Warren, W. H., Nicholas, D., \& Trabasso, T. (1979). Event chains and inferences in understanding narratives. In R. Freedle (Ed.), New directions in discourse processing. Norwood, NJ: Ablex.

Weller, S. C., \& Romney, A. K. (1988). Systematic Data Collection. London: Sage.

Zacks, J., \& Tversky, B. (2001). Event structure in perception and conception. Psychological Bulletin, 127, 3-21.

Zacks, J., Tversky, B., \& Iyer, G. (2001). Perceiving, Remembering and Communicating Structure in Events. Journal of Experimental Psychology: General, 130(1), 29-58.

Zlatev, J. (in press). Image schemas, mimetic schemas, and children's gestures. Cognitive Semiotics.

Zwaan, R. (1999). Five Dimensions of Narrative Comprehension: The Event-Indexing Model. In S. Goldman, A. Graesser \& P. van den Broek (Eds.), Narrative comprehension, causality, and coherence (pp. 93-109). Mahwah, NJ: Erlbaum.

Zwaan, R. (2008). Time in Language, Situation Models, and Mental Simulations. Language Learning, 58 (Suppl. 1), 13-26.

Zwaan, R., Radvansky, G., \& Whitten, S. (2002). Situation models and themes. In M. Louwerse \& W. van Peer (Eds.), Thematics: Interdisciplinary studies (pp. 35-53). Amsterdam/Philadelphia: John Benjamins. 
PJOS 5(2), 2013

\section{Appendix}

\section{Gesture transcripts}

The precise transcripts provide the focal passages of the gesture examples in the German original, usually with some context. The timestamps in brackets refer to the time at which the transcript begins on the respective video clip. The transcription follows the conventions used in Cienki (2008), which are based on Dubois et al. (1993) and have been adapted for gesture analysis.

$\begin{array}{lll}\begin{array}{ll}\text { paragraphs } \\ \text { underlined }\end{array} & = & \text { intonation units } \\ \wedge & = & \text { gestured part of speech } \\ \cdot & = & \text { secondary stress accent } \\ . & = & \text { final intonation, with falling pitch } \\ = & = & \text { lengthening of preceding vowel or consonant } \\ , & = & \text { terminal pitch that signals continuation } \\ <\text { AA }> & = & \text { accelerated speech tempo } \\ {[]} & = & \text { peak / stroke phase of gesture (see McNeill 1992) } \\ 2 \mathrm{H} & = & \text { both hands } \\ \text { LH } & = & \text { left hand } \\ \text { RH } & = & \text { right hand } \\ \text { PU } & = & \text { palm up } \\ \text { PD } & = & \text { palm down } \\ \text { OH } & = & \text { open hand }\end{array}$

$1 \quad$ Figure 1 - Karasek: Murakami (6:06)

2 oder wenn sie sein ['erstes ver'folgen] der wiedergefundenen ['frau durch die $\wedge$ stadt $]$

$\wedge$

$2 \mathrm{H} \mathrm{OH}$ with the palms facing each other prepare for gesture at head level, $[2 \mathrm{H} \mathrm{OH}$ stretch and descend slightly, $\mathrm{RH}$ moves left to a distance of a head's breadth, then $2 \mathrm{H}$ push far forward and upwards again] [2 $\mathrm{H}$ beat and are taken down on last beat]

\section{Figure 2 - Karasek: Murakami (0:53)}

10 [^und] 'dann passiert ihm 'folgendes,

11 [2H OH palms facing each other in front-central] then descend to a crossed rest position

$=[\mathrm{er}$ ist $]$ 'siebenund'dreißig $\wedge$ jahre alt.

[2H open to $\mathrm{OH}$ palms facing each other a head's breath apart], then they hold their position

[er 'trifft seine 'erste $\wedge$ liebe],

$2 \mathrm{H}$ beat up and down energetically, in a slight leftward motion. Beats are performed with the RH

PU while the LH stays as before and moves less and less from beat to beat]

$\frac{\text { [die er mit 'zwölf 'jahren in der 'schule geke äh }<\text { A kennenge`lernt hat } \mathrm{A}>}{\wedge \wedge}$ 
[RH PU OH performs beats, similar to the previous ones, LH stays put ...with word "jahren" camera fades out to show book, while Karasek's stroke continues

Figure 3 - Karasek cont. (1:28)

und diese be^gegnung,

HANDS NOT WELL VISIBLE

'ist auch eine 'art be^gegnung,

HANDS NOT WELL VISIBLE

$\left[\right.$ mit $\operatorname{dem}^{\wedge}$ tod],

[RH OH with slightly inside-upward turned palm rises and drops twice, followed by an expressive hold with a slightly inside and upward turned palm.]

[mit dem^^chaos].

[RH PU, palm is smoothly turned into PD position, then back again with the same expressive hold as in the previous gesture]

\section{Figure 4 - Karasek cont. (1:57)}

[weil die 'kriminal'motive verlaufen alle ${ }^{\wedge}$ blind] ins 'leere,

$2 \mathrm{H}$ rest crossed in front of the body, [then both are opened and raised in PD position and facing each other, next the palms slowly turn inwards, finally they sweep upwards with acceleration] $2 \mathrm{H}$ sink to the crossed position

\section{Figure 5 - Karasek cont. (6:18)}

wobei [der 'autor es 'wirklich ge^nial] [ver'steht],

RH to the right of the center with index finger pointing upwards, [beats on the accented syllables] [RH opens with the palm facing the speaker, moves to the left, LH OH swings upwards with the palm facing the speaker]

uns [im $\left.{ }^{\wedge} \mathrm{zweifel}\right] \mathrm{zu}$ lassen,

[one hand moving forward as the other moves backward and vice versa] then the hands become almost inanimate

ob das das [^real] oder [er'träumte] szene ist,

$2 \mathrm{H}$ sligthly lowered, [RH retracted somewhat, $\mathrm{LH}$ tense,] [RH moves forward and is tense,] $2 \mathrm{H}$ turn into PD position facing each other

\section{Figure 6 - Karasek: Schiller (4:11)}

['weil der^kai]ser ihn,

[closed RH PD with index finger pointing down moves from the rightmost position to the center, tracing an arc;the index finger's tip very briefly comes down to the initial level] RH descends

sozu'sagen ent[^täuscht hat],

$\wedge \wedge \wedge \wedge$

RH closed with bent index finger pointing left performs a beat [then, from a middle position, very rapidly moves to the right upper position with finger now pointing up in a semi-arc]

\section{Figure 7 - Willemsen: Hamsun (2:12)}

[er 'richtet eine] [^menge von ver'wirrungen] an.

RH PD OH rests on armchair, LH OH PU with palm slightly turned inwards extends far to the left [2H move further inward with cupped palms facing each other] $[2 \mathrm{H}$ rotate around the wrist slowly and easily,] then rest in central position 
PJOS 5(2), 2013

102

103

104

105

['einmal kommt sogar] eine ${ }^{\wedge}$ frau und besucht ihn,

[2H OH PU and facing each other move to the right in a slight arc while his gaze also moves to the right] $2 \mathrm{H}$ held on the right side of the body

['aber das ist] nicht ${ }^{\wedge}$ wichtig.

[2H OH PU move to the speaker's left, RH rotates the palm downwards while head turns to the left slightly] $2 \mathrm{H}$ remain frozen in that position

\section{Figure 8 - Willemsen: Schütt (1:37)}

[bei 'all diesen] ${ }^{\wedge}$ ausschnitten,

[2H cupped almost in a"pinch", palms facing center and fingers of both hands almost touching; fingers and hands tentatively trace small circles] then remain still

[die 'unter'schiedlich be] ${ }^{\wedge}$ lastbar sind,

$[2 \mathrm{H}$ raised into a flat "lid" position (PD), both make dabs starting from top-center and tracing a very flat triangle] in final position RH is held below LH

die manchmal ['rein] amü^sant sind,

[2H OH PD trace a small circle (up and inward, then down and back to the front)], then remain still

[die oft] [über^rasch]end sind,

[RH OH PD moves upwards to the level of LH with a wiggly movement] [2H OH PD taken down to the initial level of RH from previous gesture, RH thumb held close to the hand, LH thumb extended] and $2 \mathrm{H}$ held

die manchmal [n^klugen] gedanken auf‘blitzen lassen,

$2 \mathrm{H}$ loosen tension, cupped palms almost facing each other, [curled RH sweeps up to head-level,] remains in the position as the intonation phrase ends

\section{Figure 9 - Willemsen: Bouvier (1:32)}

[und 'hat] ^jetzt,

$2 \mathrm{H} \mathrm{OH}$ with palms slightly facing downwards and away from speaker; [2H move up, hand open, with palms turned slightly upwards and increasing distance,] hold

inspirat['ive ^schübe],

[starting from last position, $2 \mathrm{H}$ move in a large circle that begins with an upwards and inwards movement and the last segment of which accelerates, while the hands close in and palms turn to each other,] hold

['dann und 'wann hat er=n] ^einfall,

$[2 \mathrm{H} \mathrm{OH}$ with the palms facing each other repeat the previous circle gesture, only that the hands move apart and together again,] hold

\section{Figure 10 - (1:36, continues previous passage $)$}

'dann und 'wann [^kommt],

$2 \mathrm{H} \mathrm{OH}$ with the palms facing each other perform a small beat [then LH comes somewhat closer to $\mathrm{RH}]$

[n 'lyrisches] frag^ment,

$$
\wedge \wedge
$$

[2H sculpt a ball in front of chest with hands held opposed, but at different levels, LH PU and RH

PD; RH wrist rotates minimally twice as if for emphasis,] hold

\section{Figure 11 - (1:37, continues previous passage)}

['dann und 'wann ^geht, ] 
[2H same ball moves to the left as if creating same object anew: LH comes first and turns the palm to the inside, then RH follows and with greater tension towards the end]

[ne 'un]mittelbare ${ }^{\wedge}$ wahrnehmung,

$[2 \mathrm{H} \mathrm{OH}$ rotate palms to face forward as if holding a larger object and dart towards audience; expressive tension at the end with a small dab forward,] hold

[^über,]

[2H continue arc to the right, brief shake in center position,] minimal hold

[in ne 'existenz $]^{\wedge}$ stimmung.

[ $2 \mathrm{H}$ continue further to the right and drop a bit below level held before; expressive tension at the end,] hold

\section{Figure 12 - Willemsen: Svevo (1:13)}

in denen [^sämtliche 'fäden] des 'romans,

LH resting; RH with fingers curled and easily resting on the armchair; [2H raised to chest height, both to a closed scissors position formed by index and middle fingers that point at the audience, left hand a bit above the right] hold

'durch`schnitten werden,

\section{Figure 13 - (1:17, continues previous passage $)$}

und wir [plötzlich ^`ganz] isol'iert,

[2H opened fully to "blade" position, i.e. flat palms facing each other, slowly move upwards to the right; the terminal part of the movement has extra emphasis with $2 \mathrm{H}$ quickly pulled down; palms are now almost at body breadth,] hold

['einen ^^sohn, ]

[2H OH, palms in blade position perform beats]

am ['sterbebett $\operatorname{der}{ }^{\wedge}$ mutter] er'leben,

[repeated,] then hold

\section{Figure 14 - (1:21, continues previous passage $)$}

[in einem] ['la:ngen pro'zess der ago^nie.]

[RH open still in blade position shifts to the left until it almost touches LH] [RH OH, slowly moves back to previous position at the right; the final part of the gesture is emphasized by thrusting the taut RH downwards,] brief hold

\section{[=und erst als 'dieser] ^abge'schlossen ist,}

[LH, OH, palm facing the other hand slowly glides to the right until they almost touch,] hold

$\left[{ }^{\wedge}\right.$ setzt der 'roman] wieder 'ein.

$[\mathrm{RH} \mathrm{OH}$, palm still facing the other hand accelerates further to the right moving away from other hand,] $2 \mathrm{H}$ remain in that position

\section{Figure 15 - Willemsen: Angel Vasquez (2:33)}

[und $\operatorname{der}^{\wedge}$ stoff]lich,

2H held frontally with LH PU cupped and the thumb showing slightly upwards, RH PD curled with the stretched index finger touching the left thumb, $[\mathrm{RH}$ is lifted and fingers briefly lose contact, left index finger is extended again until it touches right index finger,] they remain in that position

was die ent'wicklung [einer ep^ ${ }^{\wedge}$ oche], 
PJOS 5(2), 2013

186

187

188

189

190

191

192

193

194

195

[2H palms are opened and move to the left of the center, with the left palm turning downwards and the right palm still facing it, then - on the stressed syllable $-2 \mathrm{H}$ a small emphatic jerk to the right follows,] brief hold

['aus dem 'geist des 'inneren mono $]^{\wedge} \operatorname{loges}$ heraus, .

[2H performs beats that accelerate, but lose emphasis; hands increasingly drop to the lower right]

['definitiv] ${ }^{\wedge}$ neuland betritt.

$2 \mathrm{H}$ retracted to a central rest, $\mathrm{LH}$ palm looking inside, $\mathrm{RH}$ half closed $\mathrm{PD}$, [the speaker shakes his head as if negating]

\section{Figure 16 - Willemsen: Richard Yates (0:16)}

[^unbedingt 'wissen zu 'wollen],

$[\mathrm{RH}$ index finger performs downward stabs to a spot 3 times, first time most emphatically, a last fourth time very tentatively]

wie die [^spannungs'linie 'die=ses 'buches],

2H almost flat with PD lifted into central position until the fingers almost touch and form a line together with the elbows, RH slightly opened $[2 \mathrm{H}$ create a smooth forward-directed structured and precise forward arc with steep rising, peak, dropping and end slope that is suddenly accelerated; hands move slightly outwards; $2 \mathrm{H}$ start beating and descend on every beat]

ver^laufen wird.

2H PD perform 2 beats with LH rising continuously while RH stays level, but slightly mimics the beats

das heisst auch

2H PD drop down further, 2 beats

zu ver[^folgen],

2H almost flat in "lid" position with fingertips facing each other [LH emphatically hinges to an about $20^{\circ}$ upward position]

[wie der 'seismische ${ }^{\wedge}$ stoß],

$[2 \mathrm{H}$ now $\mathrm{OH}$ as if grasping and at the same level again perform two beats on the stressed syllables, second beat is emphasized]

$\operatorname{der}[$ 'ganz am ^anfang dieses ro'manes] 'steht,

$\wedge \wedge \wedge \wedge \wedge \wedge \wedge \wedge$

[as before with beats getting quicker and less distinct]

Figure $17-(0: 20$, continues previous passage $)$

[sich im ^laufe] des ro'mans,

[2H shift to the right and stay there for a very brief moment]

[^auf],

[2H three-quarters open create an arc to the right with $\mathrm{RH}$ ending up slightly atop $\mathrm{LH}$, palms facing each other]

['oder ^ abbaun] wird,

$$
\wedge \wedge
$$


[2H move down to a plane almost at armchair level with PD hand curled, they descend with every beat,] hold

$[(\mathrm{H})]$ dann sind sie für das 'buch ver`loren.

$[2 \mathrm{H}$ OH PD perform a single sweeping motion in front of the body as if wiping out the previous gesture] return to armchair rests

\section{Summarized gesture examples}

\section{Willemsen: Bouvier (0:19)}

dass man das ge^fühl hat,

$2 \mathrm{H}$ half open with the palms facing each other rest frontally not far apart

n'autor [^sucht],

[2H open completely until they form a pyramid; while opening they move apart] brief hold

den [^eingang] in die 'fremde.

[2H OH palms facing to the center continue smoothly forwards and then close in to about a fist's width,] hold

[der^sucht] so'gar,

[2H OH palms move back again and enlarge the distance to previous width,] hold

das ver[^traute],

[2H OH palms move forward and close in, but not quite as far as two gestures above] brief hold

[in der ${ }^{\wedge}$ fremde].

[2H OH palms facing inside glide forward smoothly similar to the first narrowing before; they come to rest again at about a fist's width] $2 \mathrm{H}$ hold

\section{Willemsen: Schütt (1:42)}

[die oft] [über^rasch]end sind,

[RH OH PD lifted to the level of LH with a wiggly movement] [2H OH PD are sink to level of RH from the previous gesture] and remain there

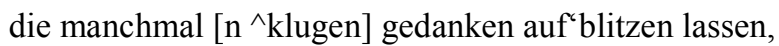

$2 \mathrm{H}$ loose tension until the palms almost face each other, [RH quickly sweeps up to head-level] and remains there

\section{Willemsen. Yates (3:07)}

und solche [zer^störungspro'zesse im] 'psychologischen ähm ver'hältnissen,

$2 \mathrm{H} \mathrm{OH}$ in central space as if grasping something with PD; then both hands slowly rise and close in until they suggest holding a ball; [ $2 \mathrm{H}$ twist in a screw-like countermotion,] rest with $\mathrm{RH}$ palm parallel to body and LH curled inwards

[auch in ^eh]en,

[2H twist once] then close a bit with palms facing body

auch das ${ }^{\wedge}$ kranken,

hold with one slight bimanual beat on the stressed syllable

an illusi^onen zum 'beispiel,

$2 \mathrm{H}$ slowly descend while speaker turns his gaze towards the audience; LH opens

sind ^ grund'themen für 'richard 'yates.

$2 \mathrm{H}$ rest with one slight beat on the main stress 
PJOS 5(2), 2013

300

301

302

303

304

305

306

307

308

309

310

311

312

313

314

315

316

317

318

319

320

321

322

323

324

325

326

327

328

329

330

331

332

333

334

335

336

337

338

339

340

341

342

343

344

345

\section{Willemsen: Klein (1:16)}

um den ['dort] ent`^standenen,

$2 \mathrm{H} \mathrm{OH}$ with the palms facing each other and held slightly downwards, [2H become completely flat with the fingers more stretched]

$[(1 \mathrm{~s})]$ 'zustand der [^un]'ordnung,

[2H PD stretch completely, RH moves in parallel over LH with very little distance between them,] short hold in that position; [2H OH PD quickly sweep apart, the fingers now facing the audience and the hands about a fist's width apart]

$\mathrm{zu} \wedge$ nutzen,

$\wedge$

$2 \mathrm{H} \mathrm{OH} \mathrm{PD}$ hold the position and beat on the main stress

Willemsen: Klein (2:22)

und man [^hat das ge'fühl],

$2 \mathrm{H}$ half open with the fingertips touching each other, palms facing towards speaker, $\mathrm{RH}$ slightly higher than LH; $2 \mathrm{H}$ touch each other and [beat on the stressed syllables]

dass die ['sehr ^ ${ }^{\wedge}$ pro-'a]merikanische 'berichter'stattung,

[2H move slightly upwards with palms rotating downwards, the thumb's tip only touching the index finger's as when pinching, then $2 \mathrm{H}$ move to the right with beats] next they open a bit, right $\mathrm{PD}$, left palm faces inwardly and remains immobile

\section{Willemsen: Tolstoi (2:32)}

und tat['sächlich bloß ge $]^{\wedge}$ labelt er'scheint,

$2 \mathrm{H}$ at rest, [RH OH with thumb, index finger and middle finger stretched as if presenting a small square object to the audience traces a line in rapid and small dabs), then the hand sinks down to the armchair

[aber nicht] von 'innen [ent`]wickelt,

[relaxed $2 \mathrm{H}$ retracted into center again until fingers almost touch with flat palms held parallel to body] $2 \mathrm{H}$ descend slightly in preparation for the next gesture with palms slightly turned downwards, $[2 \mathrm{H} \mathrm{OH}$ quickly sweep upwards and outwards with palms now slightly opening to the audience]

[bloß $\wedge^{\wedge}$ be]schrieben,

$2 \mathrm{H}$ move into a quick, flat leftward arc with an end position emphasized to the far upper left] then $2 \mathrm{H}$ move back to the central position, $\mathrm{OH} \mathrm{PD}$

aber [nicht ${ }^{\wedge}$ aus] ge ‘drückt wird,

[2H OH PD energetically rotate the palms upwards and to the audience, then the circular motion drops and moves away laterally], $2 \mathrm{H} \mathrm{OH}$ facing down with fingers between cupped and curled sink back to armchair 